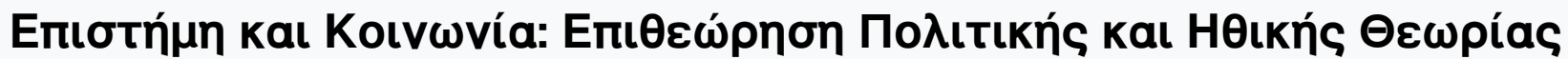

Tó 19 (2008)

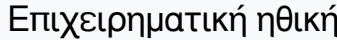

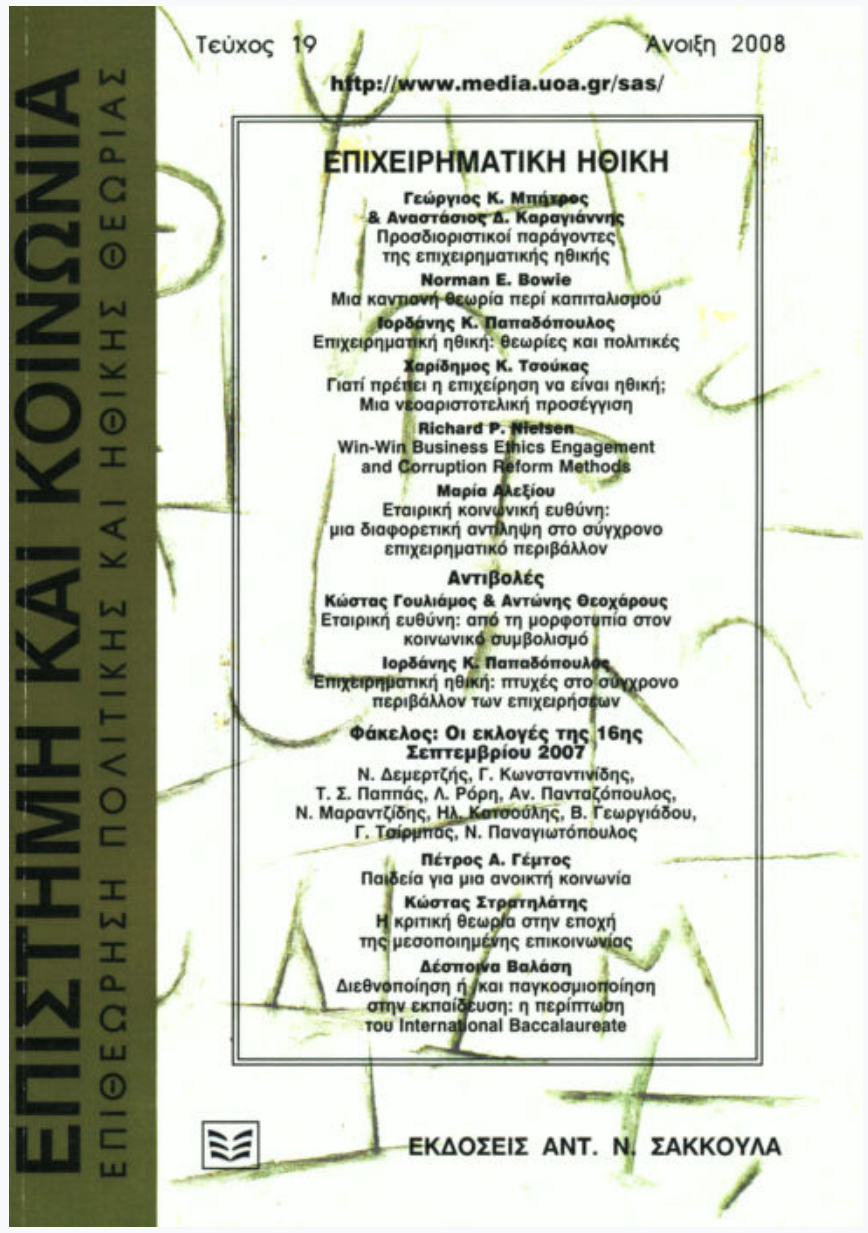

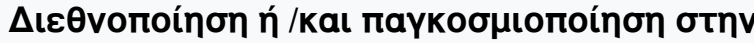 $\varepsilon \kappa \pi a i ́ \delta \varepsilon \cup \sigma \eta: n \pi \varepsilon \rho i ́ \pi \tau \omega \sigma \eta$ тou International Baccalaureate}

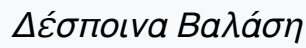

doi: $10.12681 /$ sas. 675

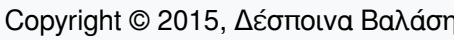

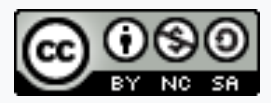

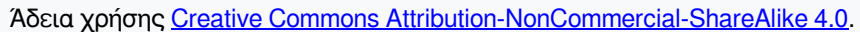

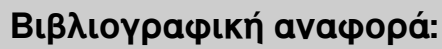

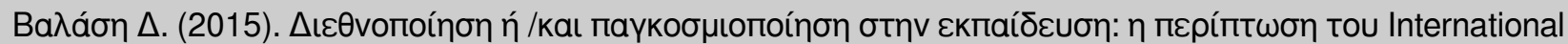

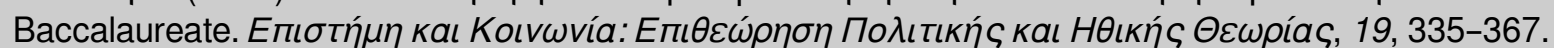
https://doi.org/10.12681/sas.675 


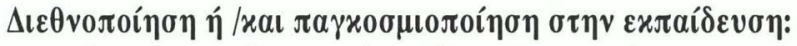

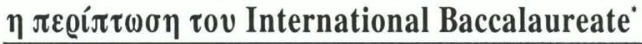

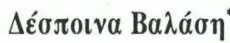

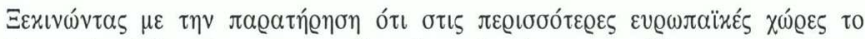

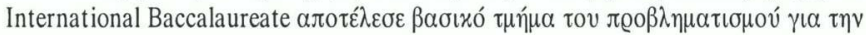

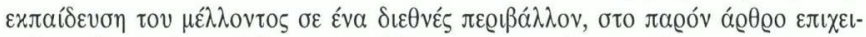

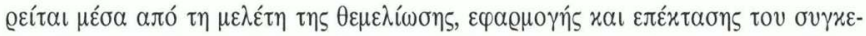

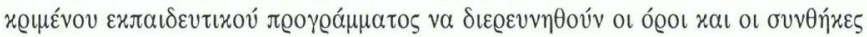

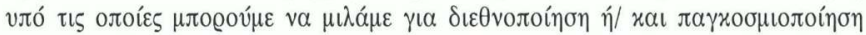

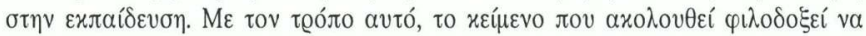

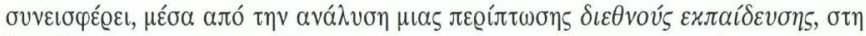

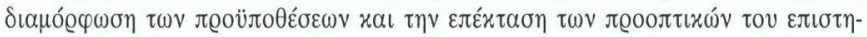

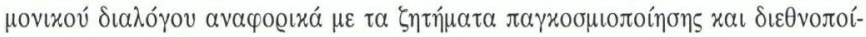

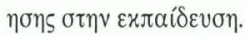

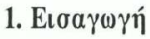

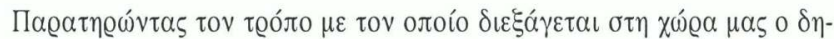

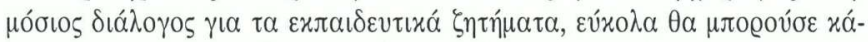

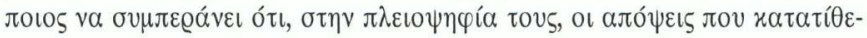

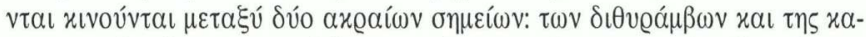

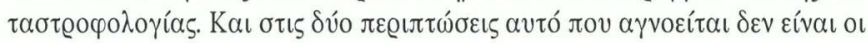

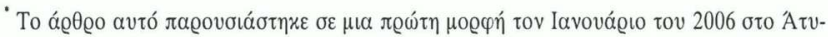

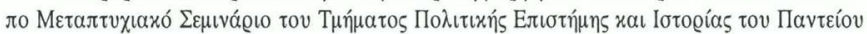

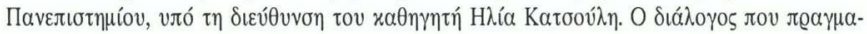

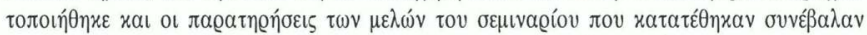

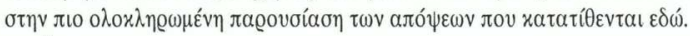

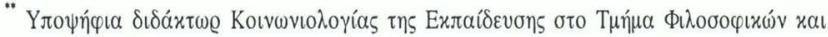

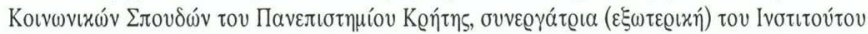

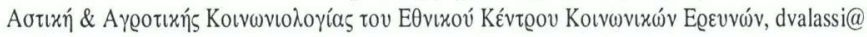
gmail.com. 


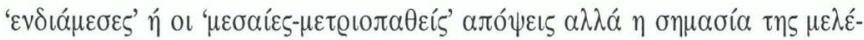

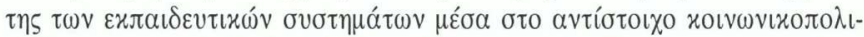

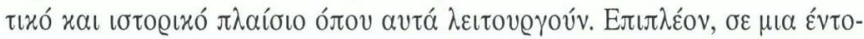

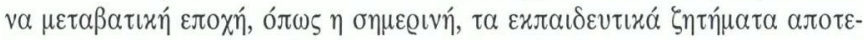

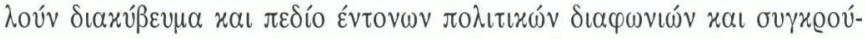

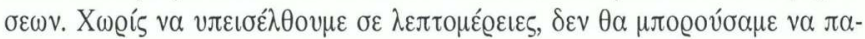

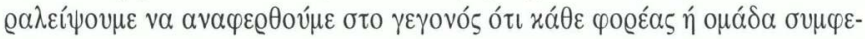

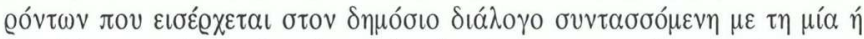

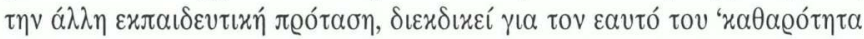

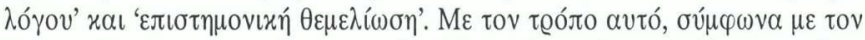

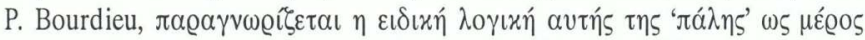

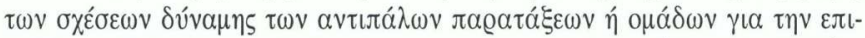

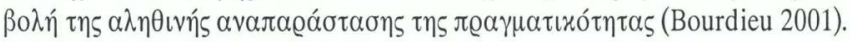

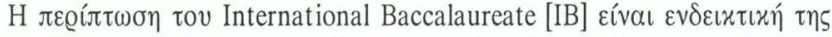

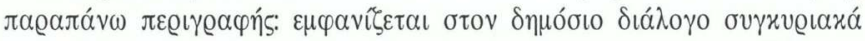

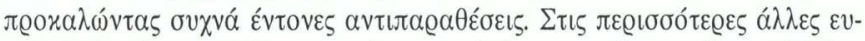

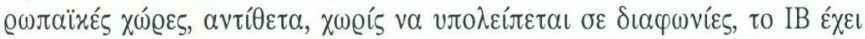

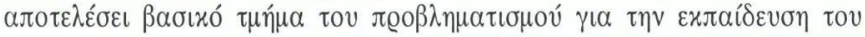

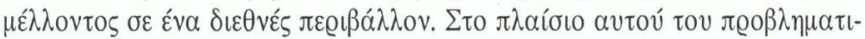

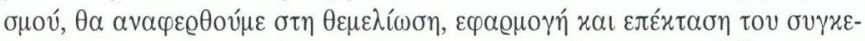

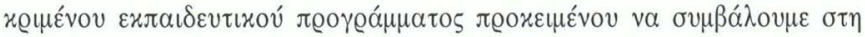

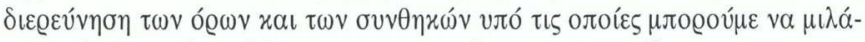

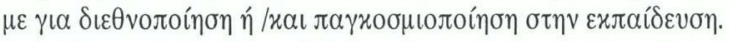

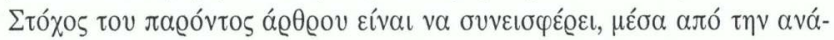

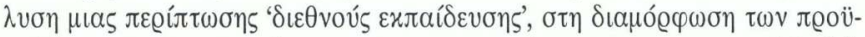

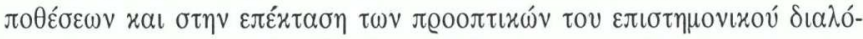

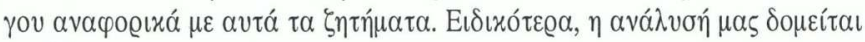

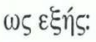

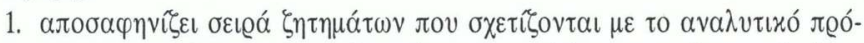

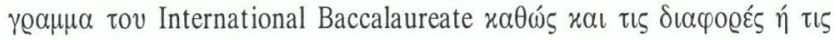

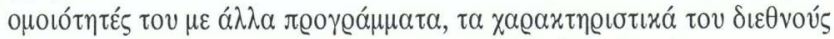

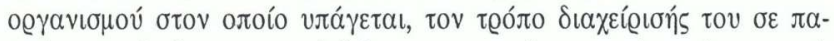

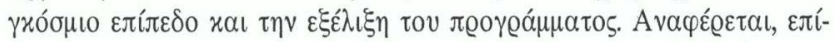

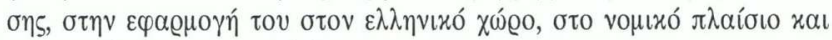

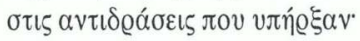




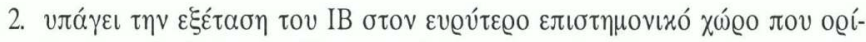

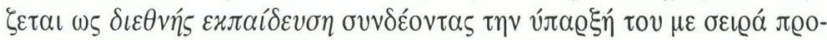

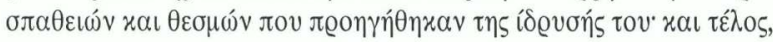

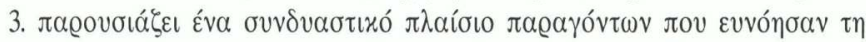

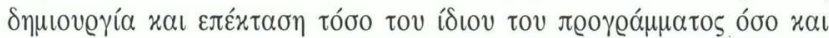
tov International Baccalaureate Organization.

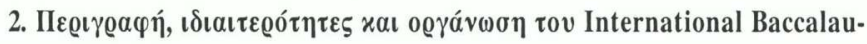 reate}

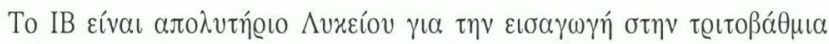

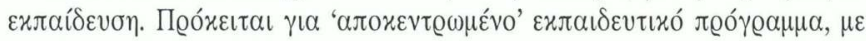

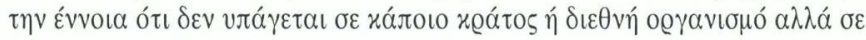

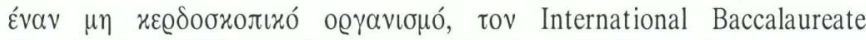

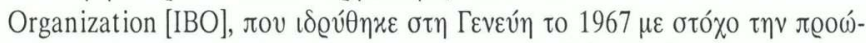

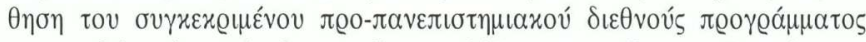

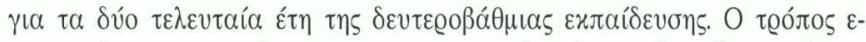

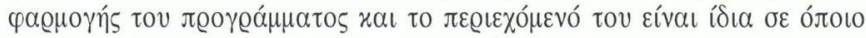

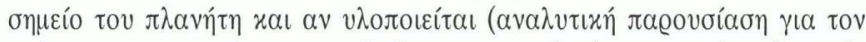

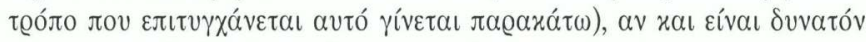

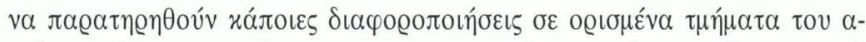

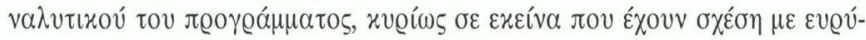

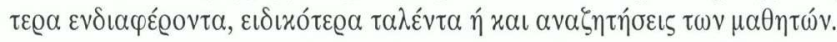

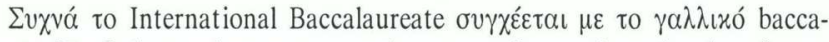

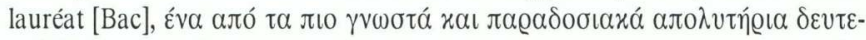

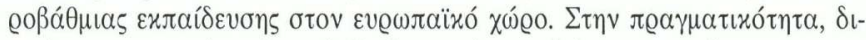

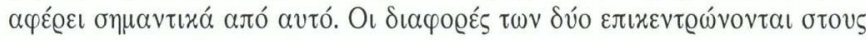

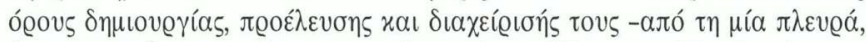

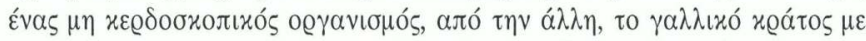

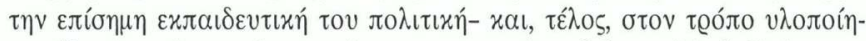

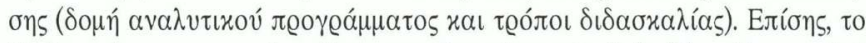

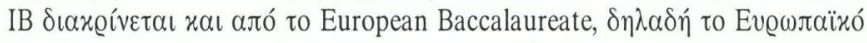

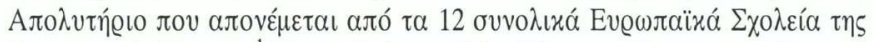

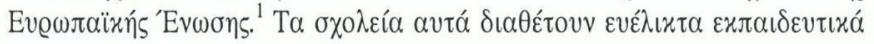

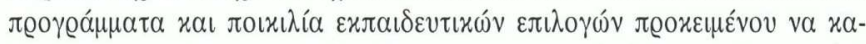

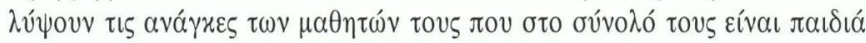




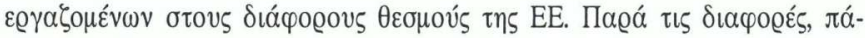

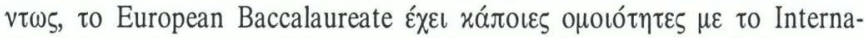

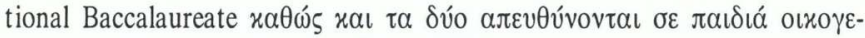

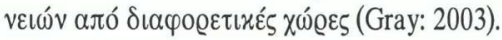

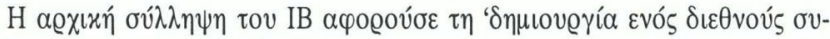

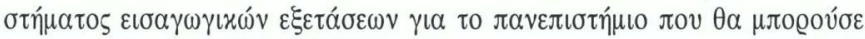

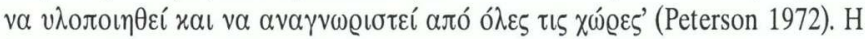

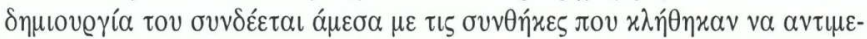

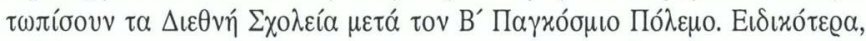

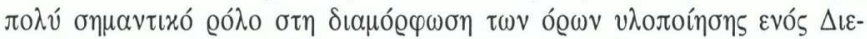

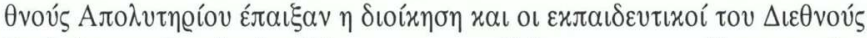

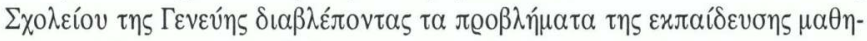

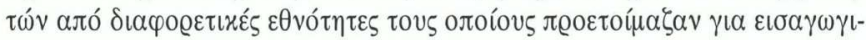

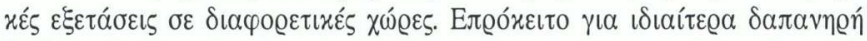

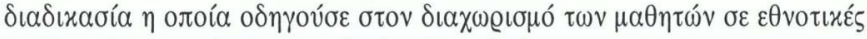

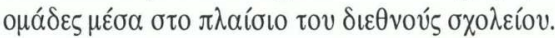

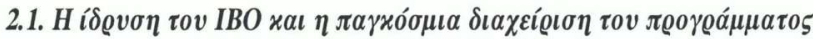

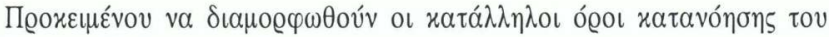

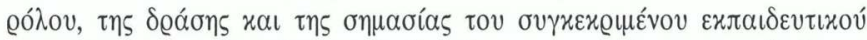

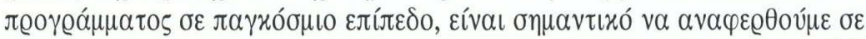

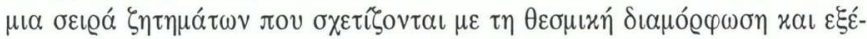

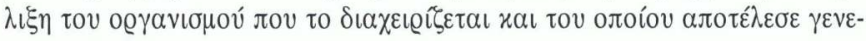

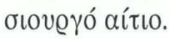

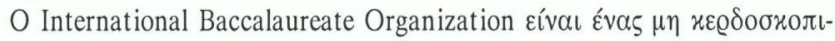

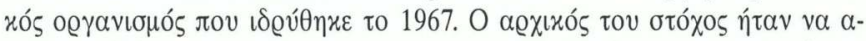

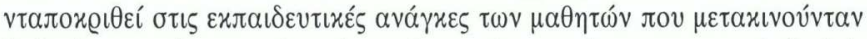

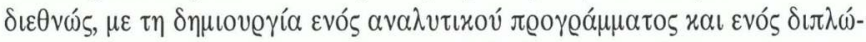

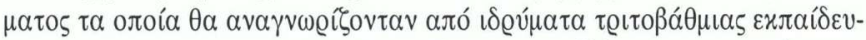

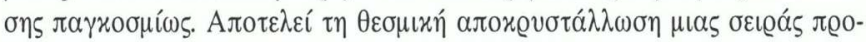

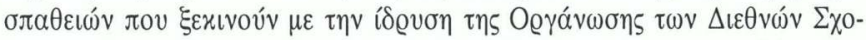

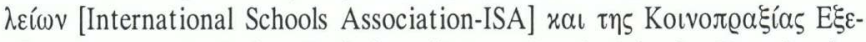

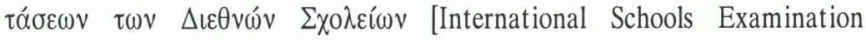

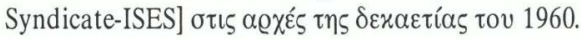




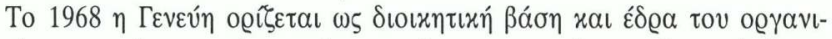

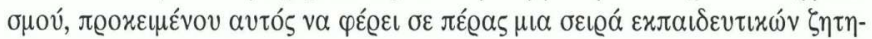

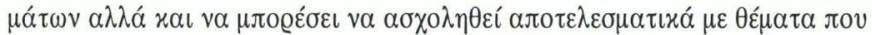

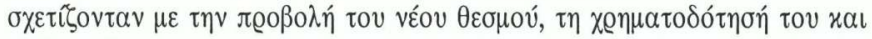

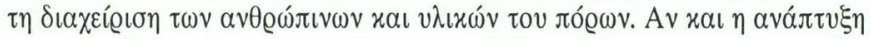

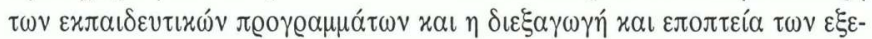

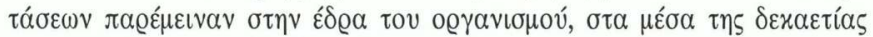

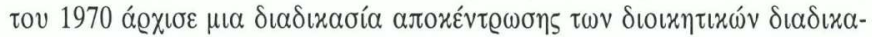
oเ

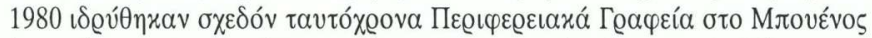

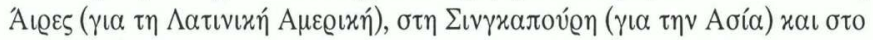

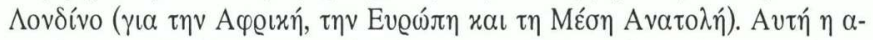

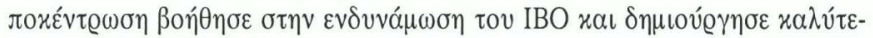

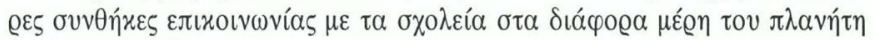
(Hill 2002: 199).

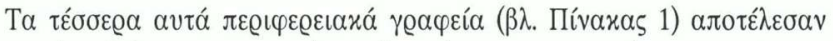

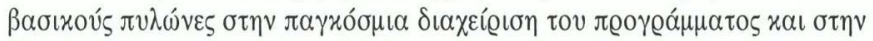

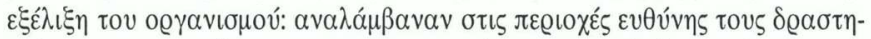

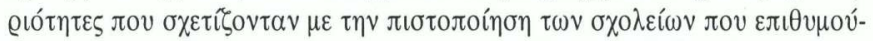

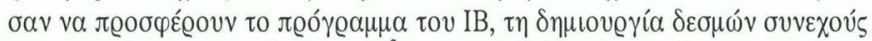

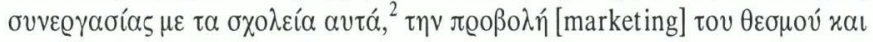

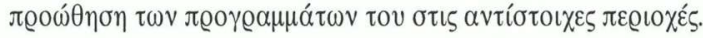

IÍvaxas 1

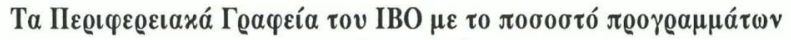

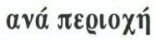

\begin{tabular}{|c|c|c|}
\hline 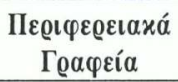 & 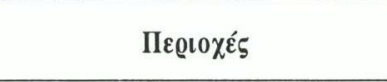 & Поooooró \\
\hline IBAEM & IBO - Africa/Europe/Middle East & $27 \%$ \\
\hline IBAP & IBO - Asia - Pacific & $13 \%$ \\
\hline IBLA & IBO - Latin America & $11 \%$ \\
\hline \multirow[t]{2}{*}{ IBNA } & IBO - North America & $49 \%$ \\
\hline & ¿úvoho & $100 \%$ \\
\hline
\end{tabular}

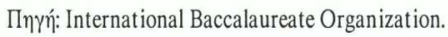




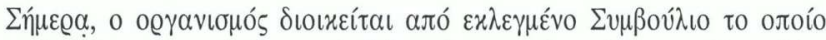

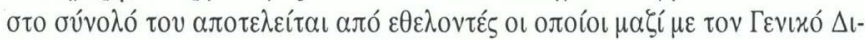

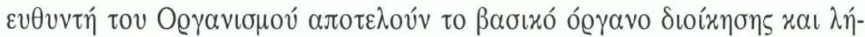

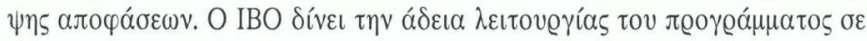

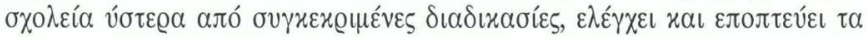

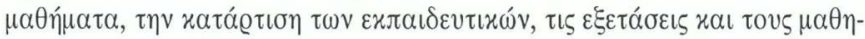

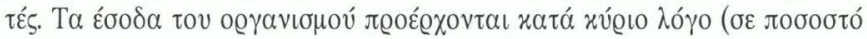

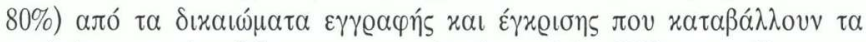

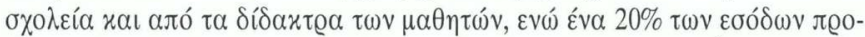

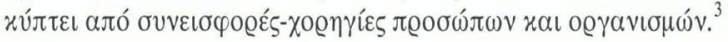

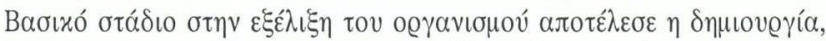

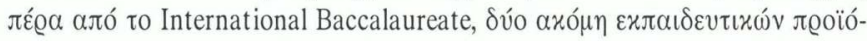

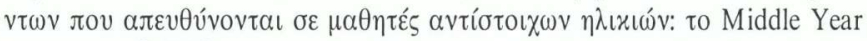

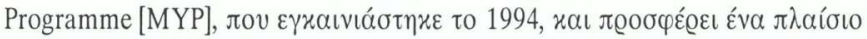

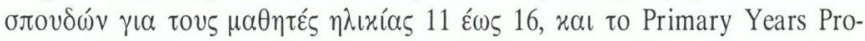

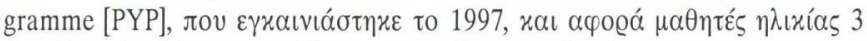

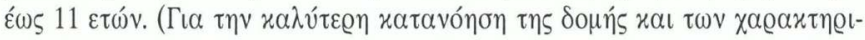

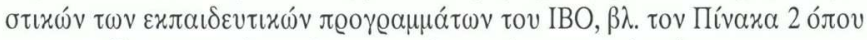

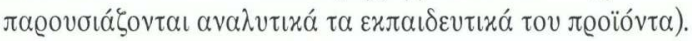

\section{Ilívaxas 2}

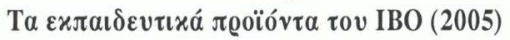

\begin{tabular}{|c|c|c|}
\hline Тіє & Aqpoeá & 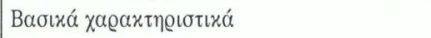 \\
\hline \multirow[t]{2}{*}{$\begin{array}{l}\text { Primary Years } \\
\text { Programme }\end{array}$} & 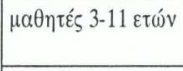 & 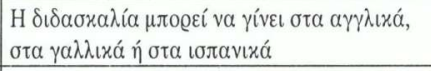 \\
\hline & 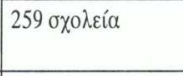 & 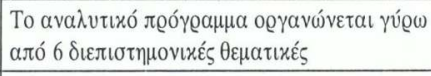 \\
\hline \multirow[t]{2}{*}{$\begin{array}{l}\text { Middle Years } \\
\text { Programme }\end{array}$} & 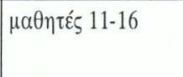 & 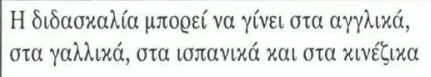 \\
\hline & 491 бходعía & 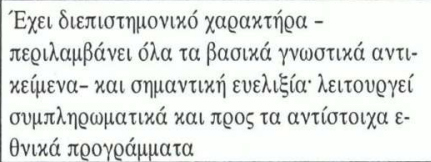 \\
\hline
\end{tabular}




\begin{tabular}{|c|c|c|}
\hline 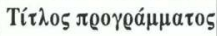 & Aqo@á & 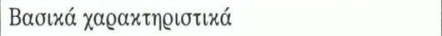 \\
\hline \multirow[t]{3}{*}{ Diploma Programme } & 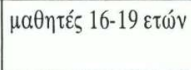 & 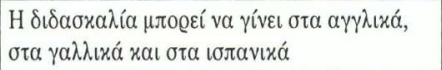 \\
\hline & 1373 бхоһеía & 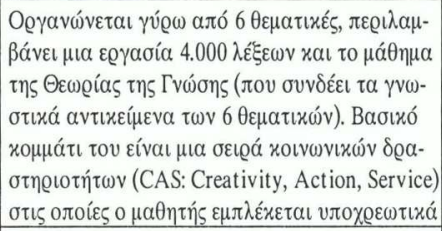 \\
\hline & & 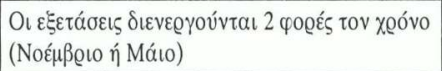 \\
\hline
\end{tabular}

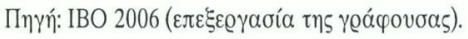

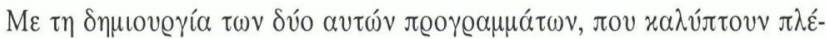

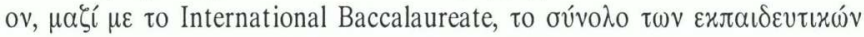

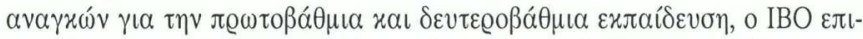

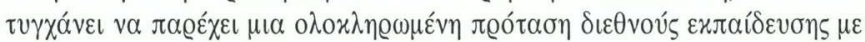

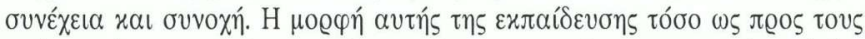

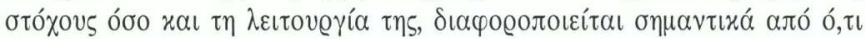

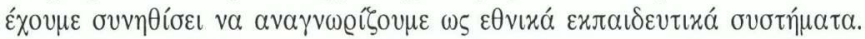

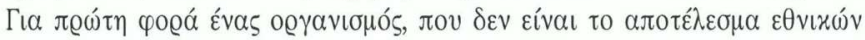

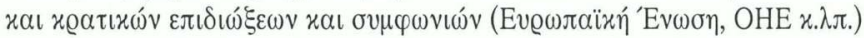

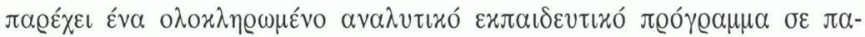

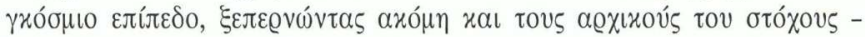

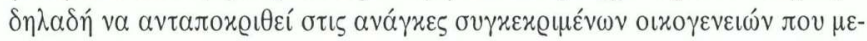

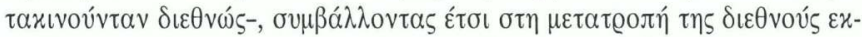

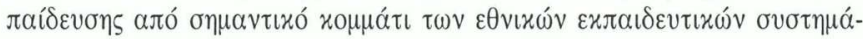

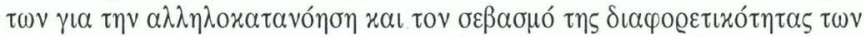

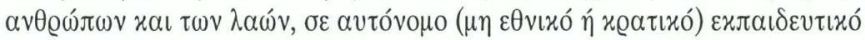

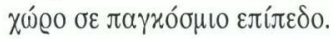

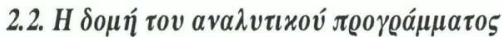

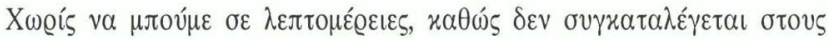

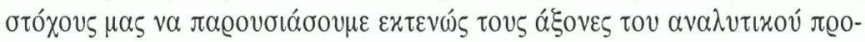




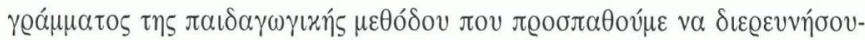

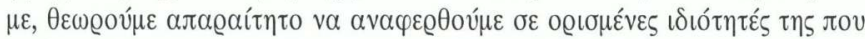

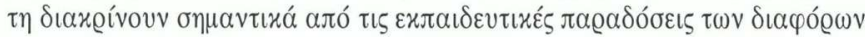

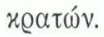

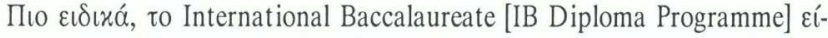

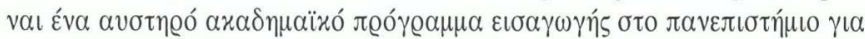

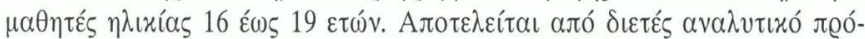

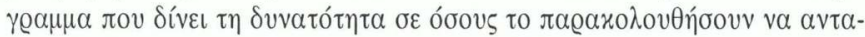

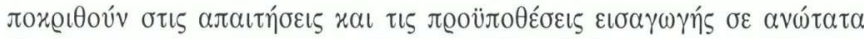

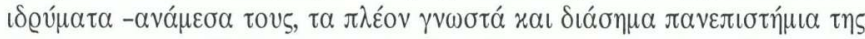

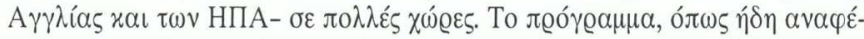

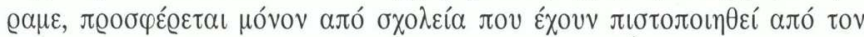

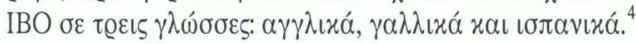

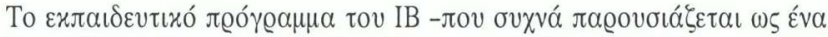

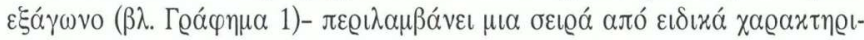

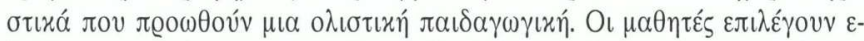

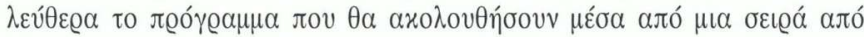

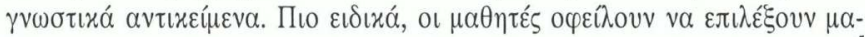

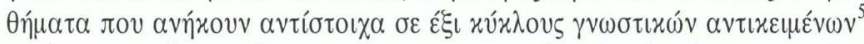

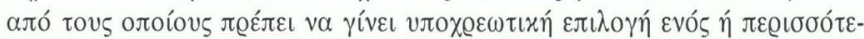

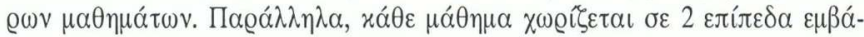

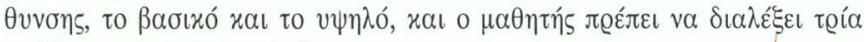

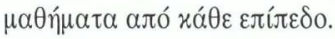

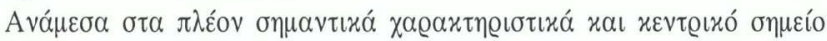

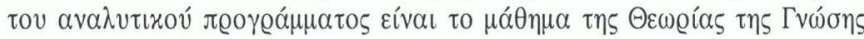

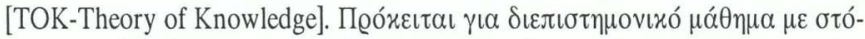

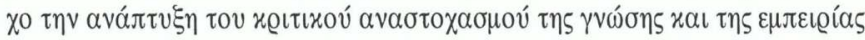

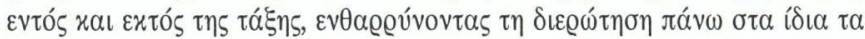

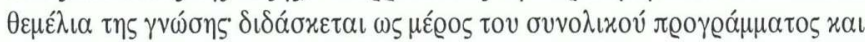

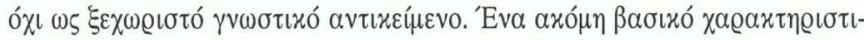

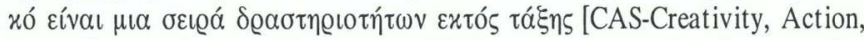

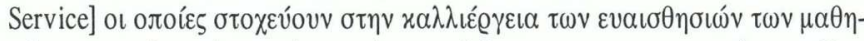

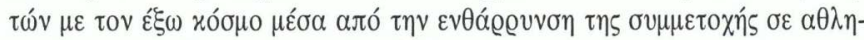

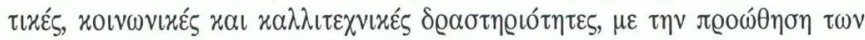
$\alpha \tau 0 \mu$ น 


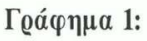

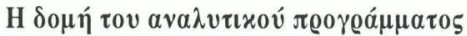

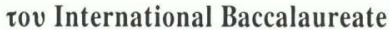

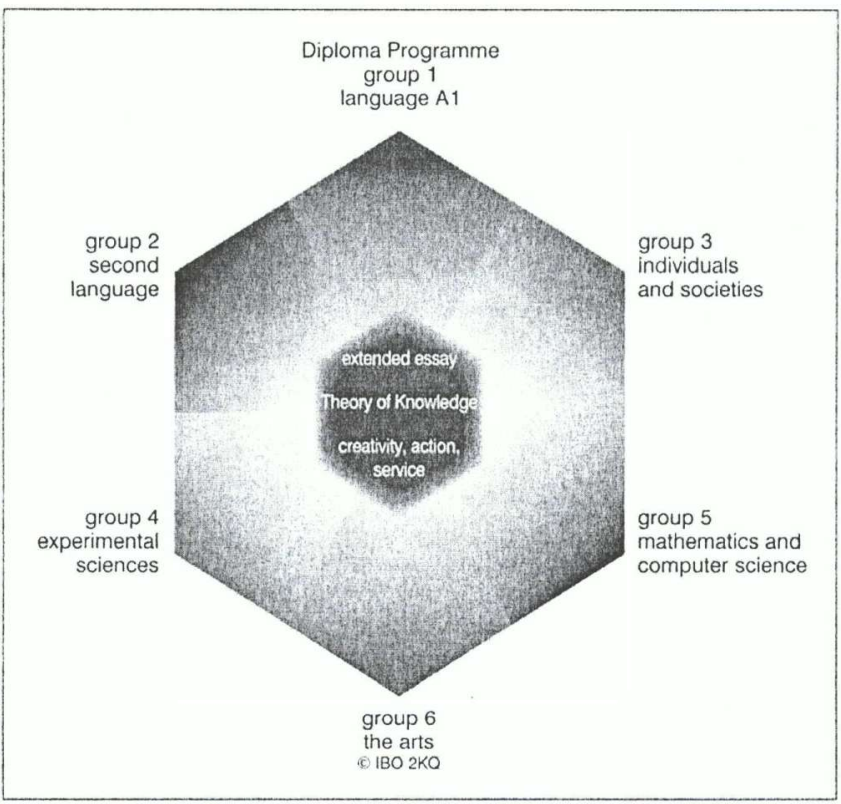

ПНГН: IBO 2006.

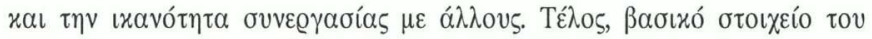

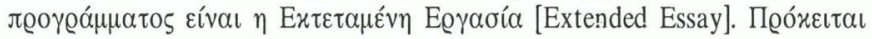

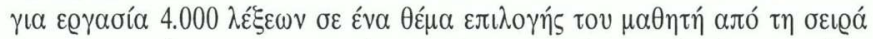

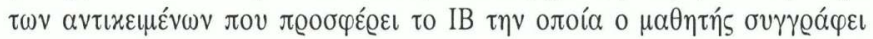

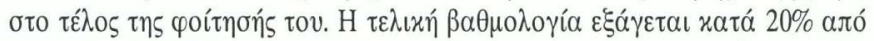

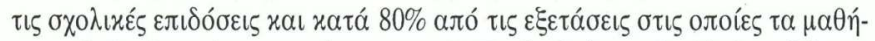

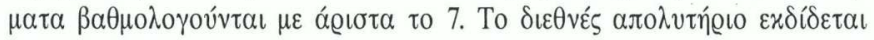




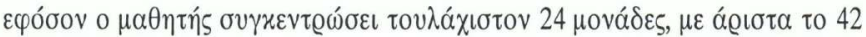

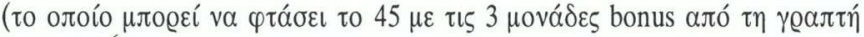

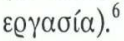

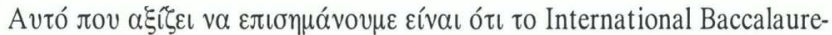

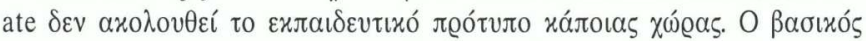

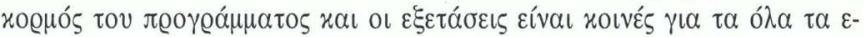

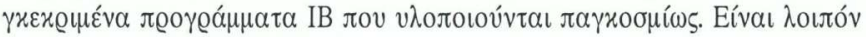

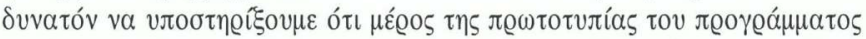

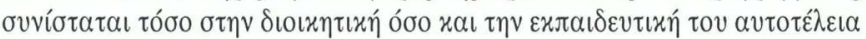

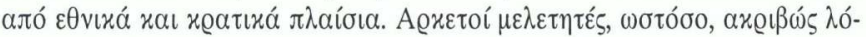

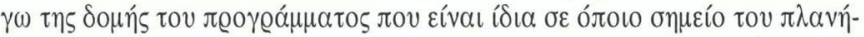

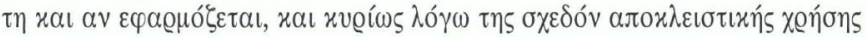

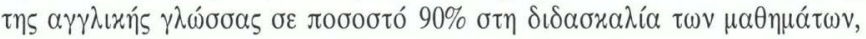

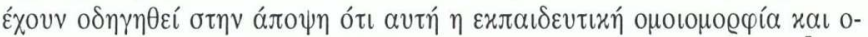

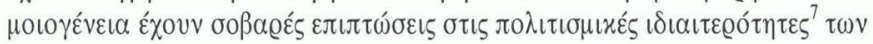

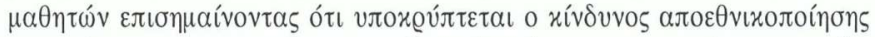

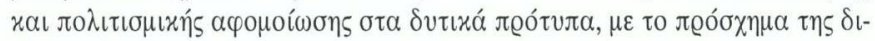
$\varepsilon \theta$ vолоínоп.

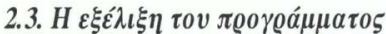

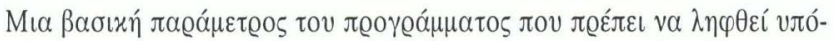

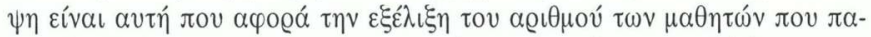

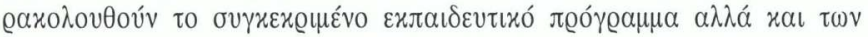

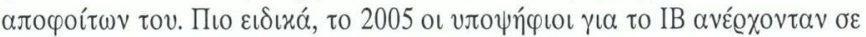

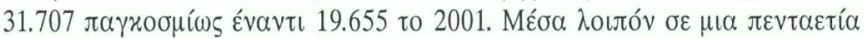

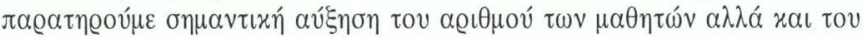

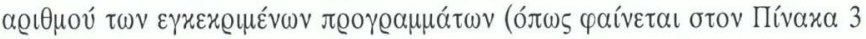

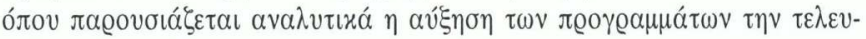

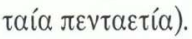

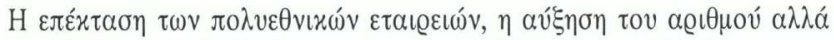

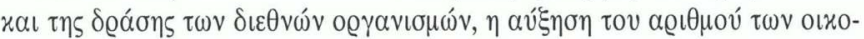

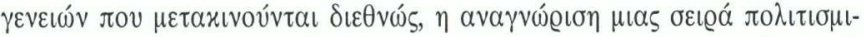

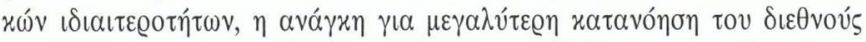

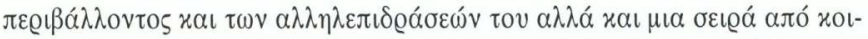

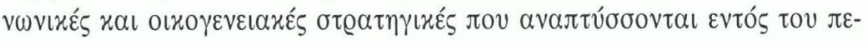




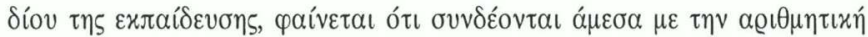

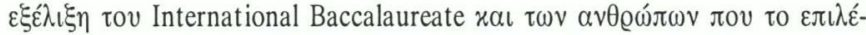

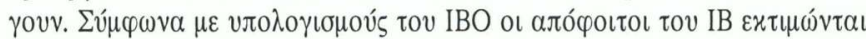

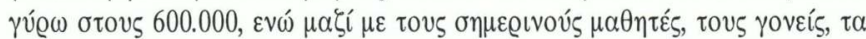

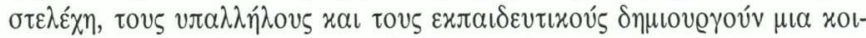

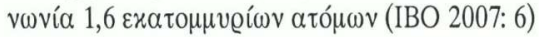

\section{Пivaxas 3}

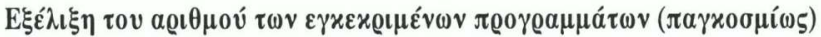

\begin{tabular}{|l|c|c|c|c|c|c|}
\hline & $\mathbf{2 0 0 1}$ & $\mathbf{2 0 0 2}$ & $\mathbf{2 0 0 3}$ & $\mathbf{2 0 0 4}$ & $\mathbf{2 0 0 5}$ & $\mathbf{2 0 0 6}$ \\
\hline Diploma & 1002 & 1060 & 1120 & 1228 & 1347 & 1489 \\
\hline MYP & 197 & 225 & 254 & 302 & 334 & 517 \\
\hline PYP & 71 & 97 & 134 & 193 & 245 & 315 \\
\hline Eúvo $\lambda_{0}$ & 1270 & 1382 & 1508 & 1723 & 1926 & 2321 \\
\hline
\end{tabular}

Ппүฑ: IBO 2005.

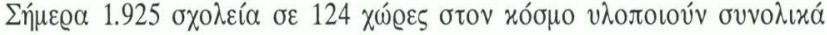

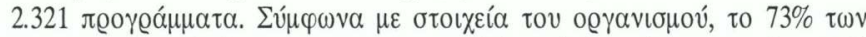

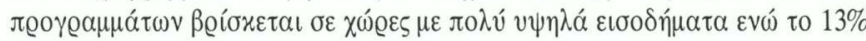

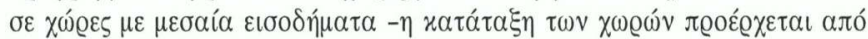

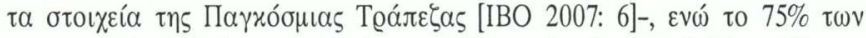

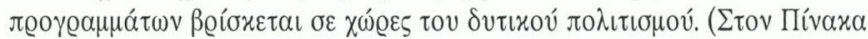

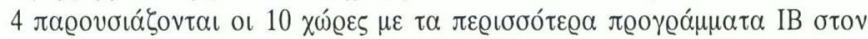
xóøuo).

\section{Пívaxas 4}

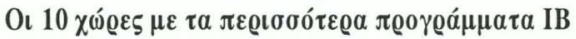

\begin{tabular}{|c|c|c|c|c|c|}
\hline & \multirow[b]{2}{*}{ Xúga } & \multirow{2}{*}{ 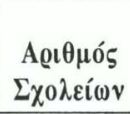 } & \multicolumn{3}{|c|}{ 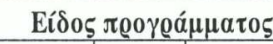 } \\
\hline & & & PYP & MYP & $\mathrm{DP}$ \\
\hline 1 & НПА & 684 & 72 & 168 & 522 \\
\hline 2 & 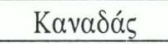 & 225 & 21 & 118 & 102 \\
\hline 3 & 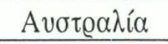 & 93 & 25 & 44 & 43 \\
\hline 4 & 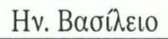 & 89 & 4 & 6 & 87 \\
\hline
\end{tabular}




\begin{tabular}{|c|c|c|c|c|c|}
\hline & \multirow[b]{2}{*}{ Xúga } & \multirow{2}{*}{ 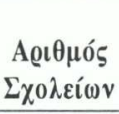 } & \multicolumn{3}{|c|}{ 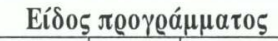 } \\
\hline & & & PYP & MYP & DP \\
\hline 5 & 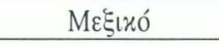 & 58 & 26 & 13 & 39 \\
\hline 6 & 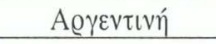 & 43 & 6 & 6 & 42 \\
\hline 7 & 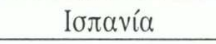 & 36 & 2 & 6 & 35 \\
\hline 8 & 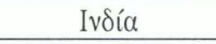 & 32 & 5 & 4 & 30 \\
\hline 9 & 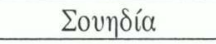 & 32 & 5 & 7 & 28 \\
\hline 10 & Kiv $\alpha$ & 31 & 6 & 6 & 25 \\
\hline & 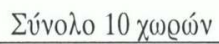 & 1323 & 172 & 378 & 953 \\
\hline & 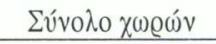 & 2321 & 315 & 517 & 1489 \\
\hline & 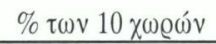 & $57 \%$ & $55 \%$ & $73 \%$ & $64 \%$ \\
\hline
\end{tabular}

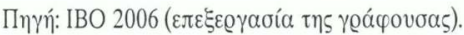

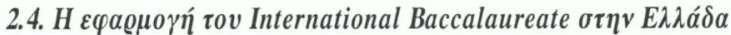

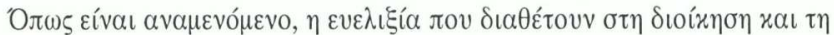

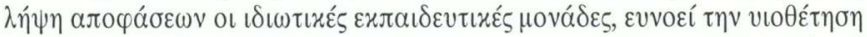

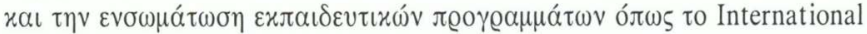

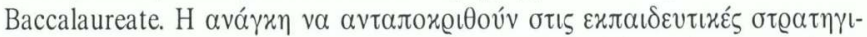

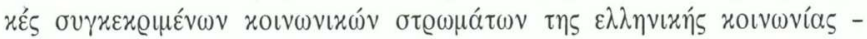

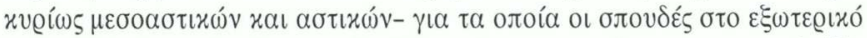

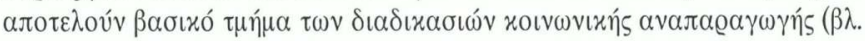

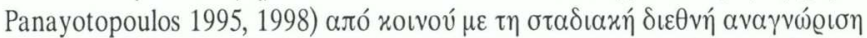

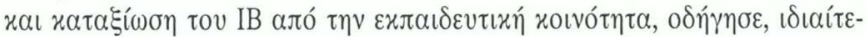

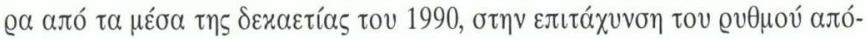

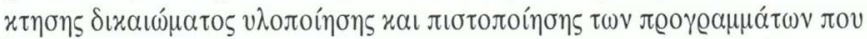

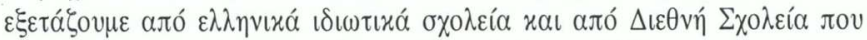

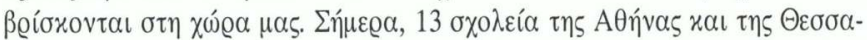

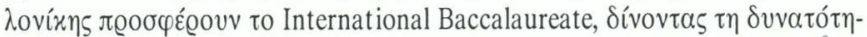

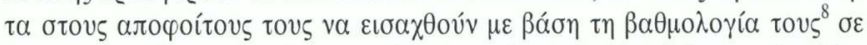

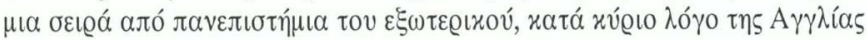




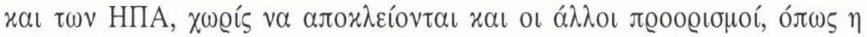

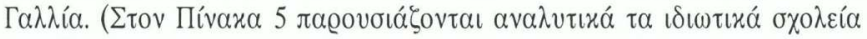

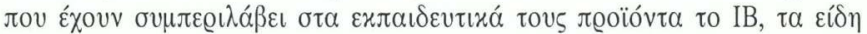

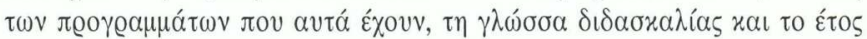
льотолоі́пฑ ало́ тоv IBO).

\section{Ilvaxas 5:}

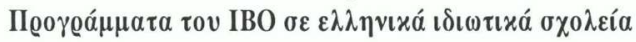

\begin{tabular}{|c|c|c|c|c|c|c|c|}
\hline & \multirow{2}{*}{ 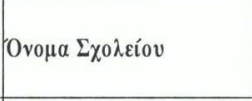 } & \multirow{2}{*}{ Nouós } & \multicolumn{3}{|c|}{ 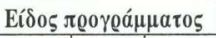 } & \multirow{2}{*}{$\begin{array}{l}\Gamma \lambda \omega \sigma \sigma \alpha \\
\delta เ \delta / \lambda i \alpha_{5}\end{array}$} & \multirow{2}{*}{ 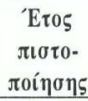 } \\
\hline & & & PYP & MYP & DP & & \\
\hline 1 & $\begin{array}{l}\text { American Community } \\
\text { School }\end{array}$ & 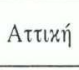 & $*$ & * & $*$ & $\alpha \gamma \gamma \lambda \iota\llcorner\alpha \dot{\alpha}$ & 1976 \\
\hline 2 & Anatolia College & $\Theta \varepsilon \sigma / \varkappa \eta$ & & & $*$ & $\alpha \gamma \gamma \lambda \iota x \alpha ́$ & 1997 \\
\hline 3 & Campion School & 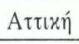 & & & $*$ & $\alpha \gamma \gamma \lambda i x \alpha \dot{\alpha}$ & 2000 \\
\hline 4 & 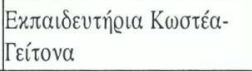 & 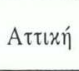 & & & * & $\alpha \gamma \gamma \lambda เ \varkappa \alpha ́$ & 1994 \\
\hline 5 & 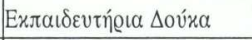 & 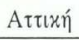 & & & $*$ & $\alpha \gamma \gamma \lambda \iota x \alpha$ & 2001 \\
\hline 6 & 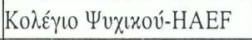 & 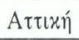 & & & $*$ & $\alpha \gamma \gamma \lambda \iota เ \alpha \alpha$ & 1996 \\
\hline 7 & 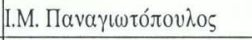 & 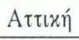 & & & $*$ & $\alpha \gamma \gamma \lambda \iota \varkappa \alpha$ & 1996 \\
\hline 8 & $\begin{array}{l}\text { TASIS-International } \\
\text { School of Athens }\end{array}$ & 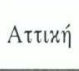 & $*$ & $*$ & $*$ & $\alpha \gamma \gamma \lambda\llcorner x \alpha ́$ & 2000 \\
\hline 9 & 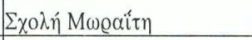 & $\mathrm{A} \tau \tau ו x \eta ́$ & & & $*$ & $a \gamma \gamma \lambda\llcorner\propto \alpha \dot{\alpha}$ & 1984 \\
\hline 10 & 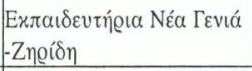 & $\mathrm{A} \tau \tau \iota x \eta^{\prime}$ & & & $*$ & $\alpha \gamma \gamma \lambda\llcorner x \alpha ́$ & 2006 \\
\hline 11 & Pinewood Schools & $\Theta \varepsilon \sigma / x \eta$ & & & $*$ & $\alpha \gamma \gamma \lambda i x \alpha ́$ & 1999 \\
\hline 12 & $\begin{array}{l}\text { St. Catherine British } \\
\text { Embassy }\end{array}$ & 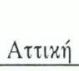 & & & * & $\alpha \gamma \gamma \lambda เ \alpha \alpha$ & 2002 \\
\hline 13 & 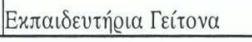 & 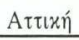 & & & $*$ & $\alpha \gamma \gamma \lambda \iota x \alpha$ & 1995 \\
\hline
\end{tabular}

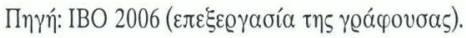

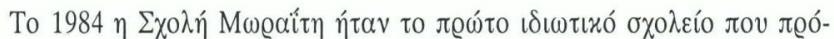

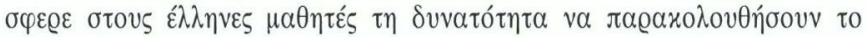

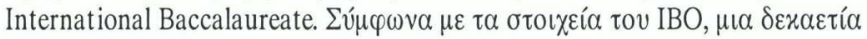




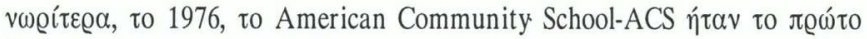

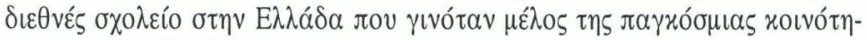

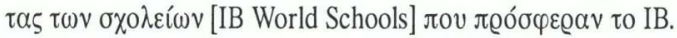

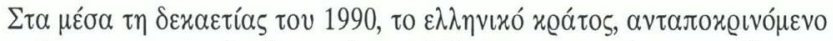

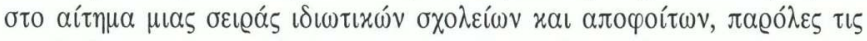

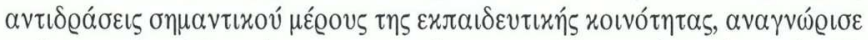

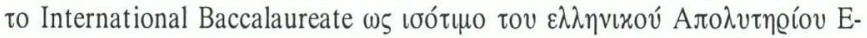

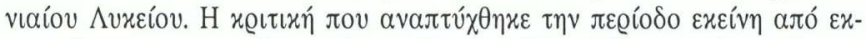

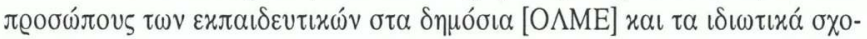

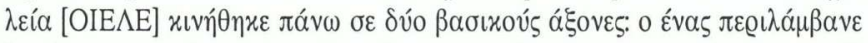

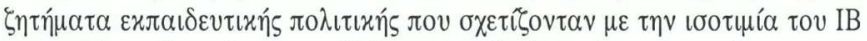

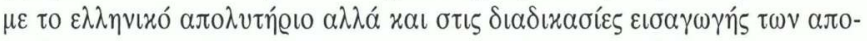

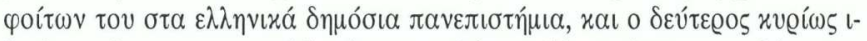

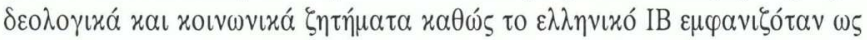

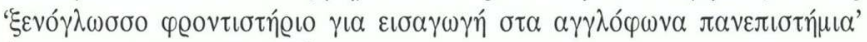

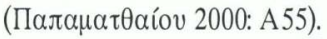

O vó

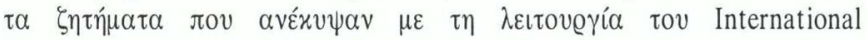

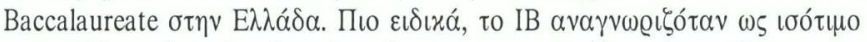

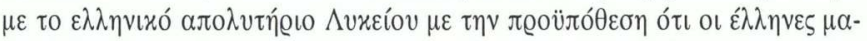

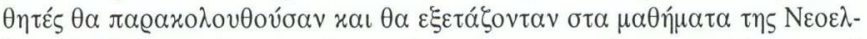

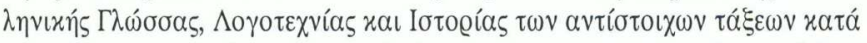

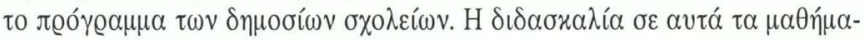

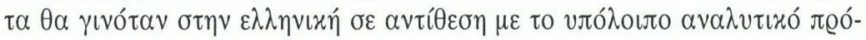

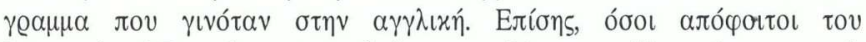

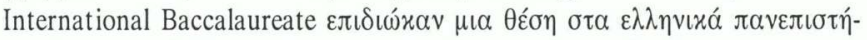

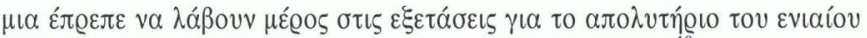

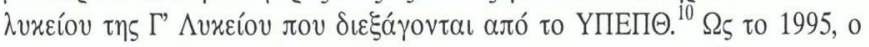

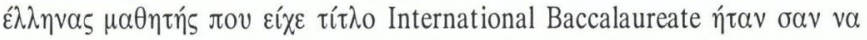

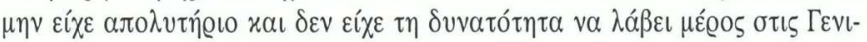

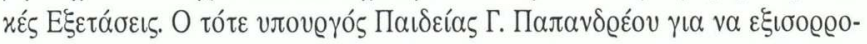

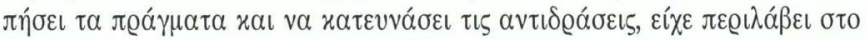

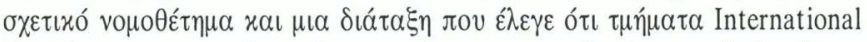

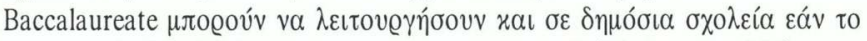

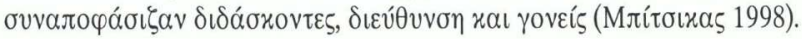




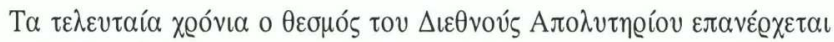

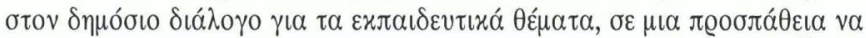

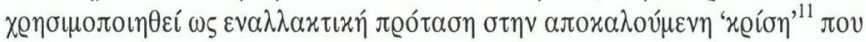

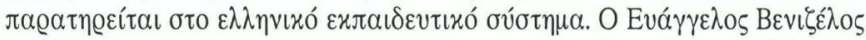

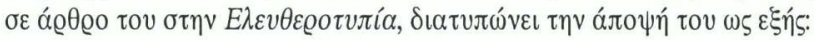

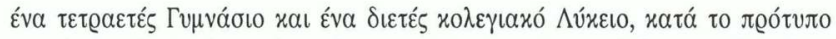

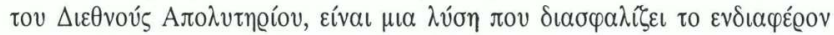

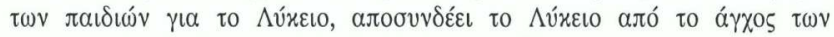

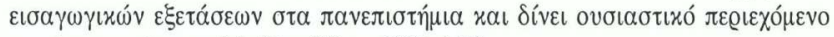

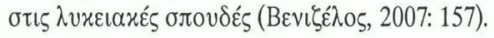

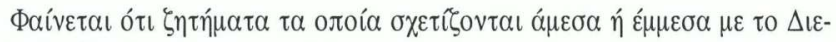

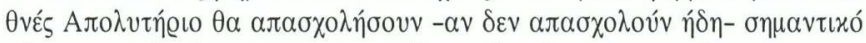

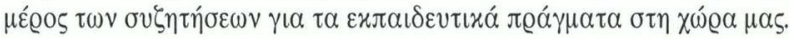

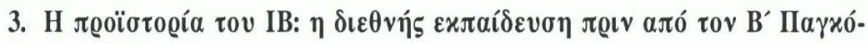

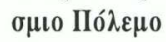

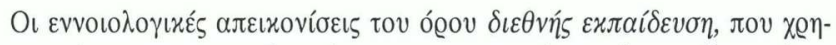

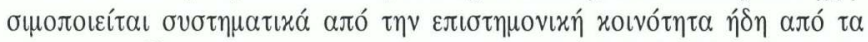

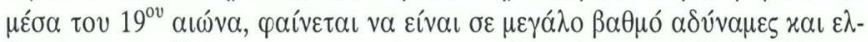

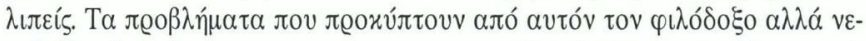

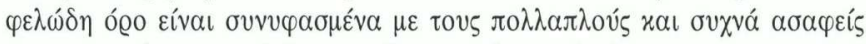

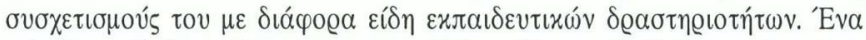

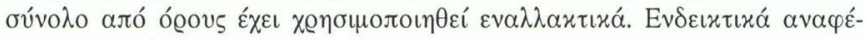

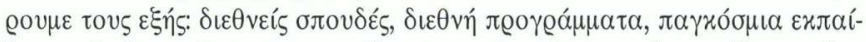

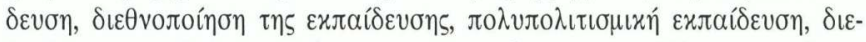

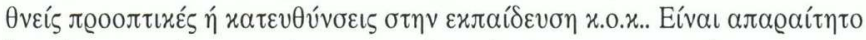

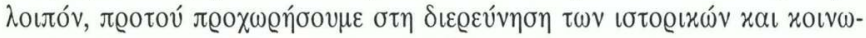

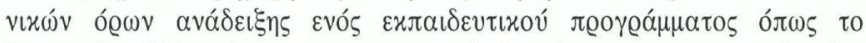

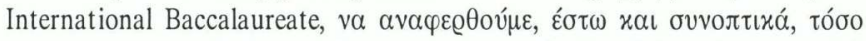

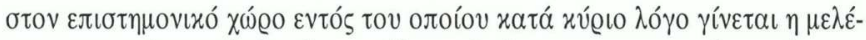

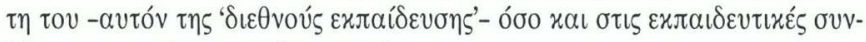

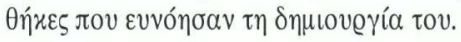




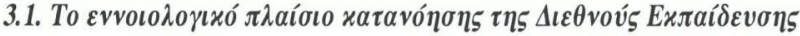

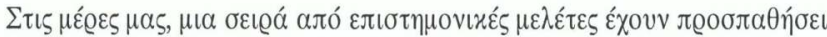

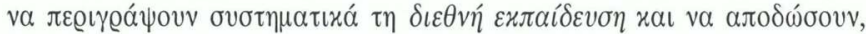

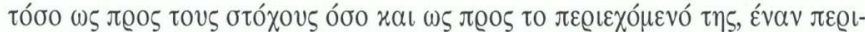

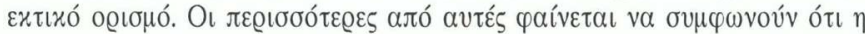

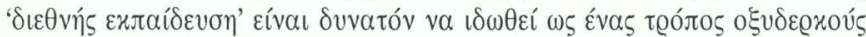

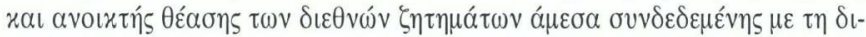

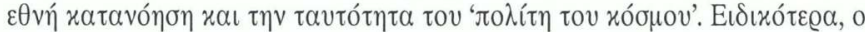

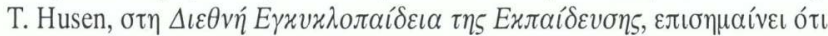

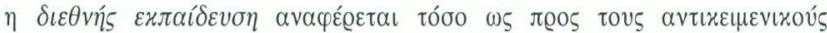

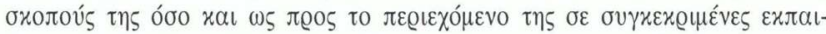

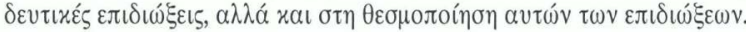

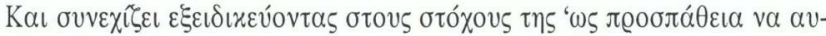

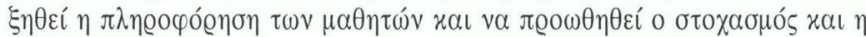

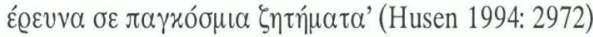

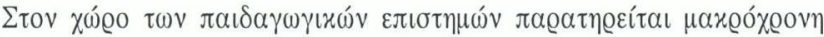

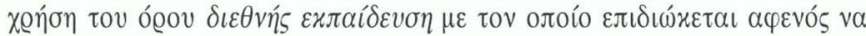

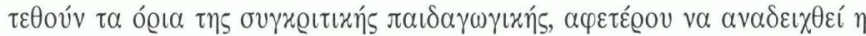

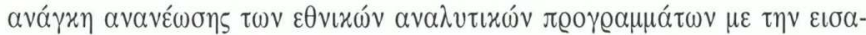

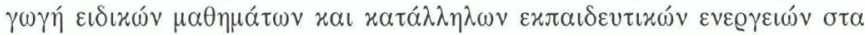

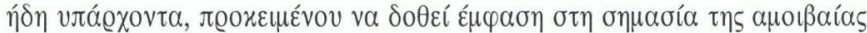

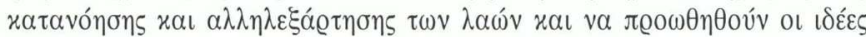

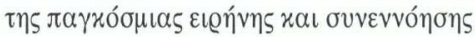

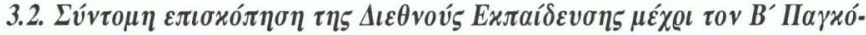

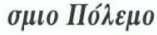

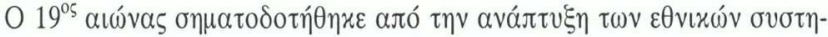

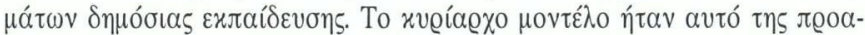

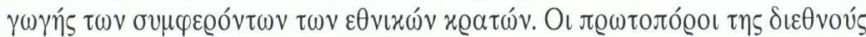

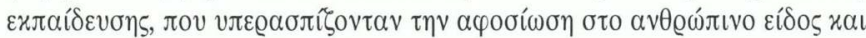

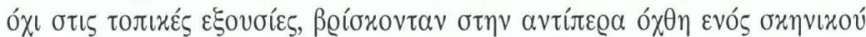

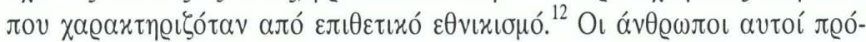

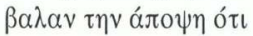




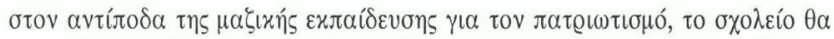

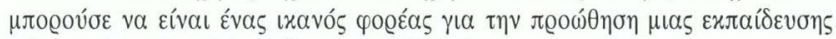

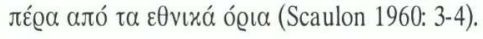

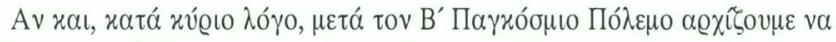

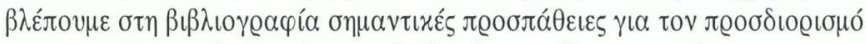

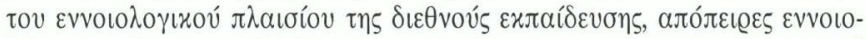

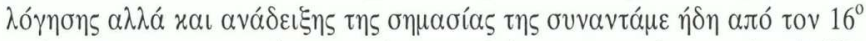

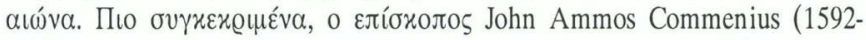

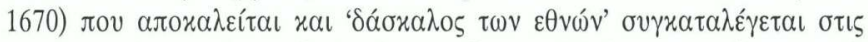

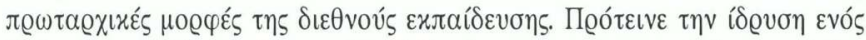

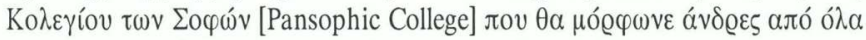

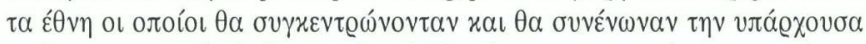

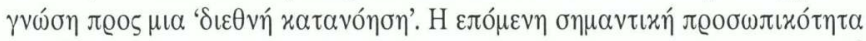

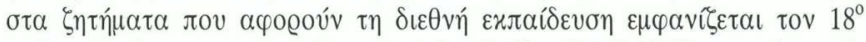

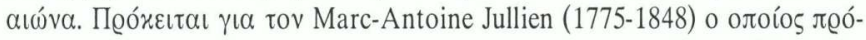

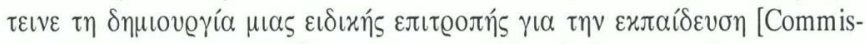

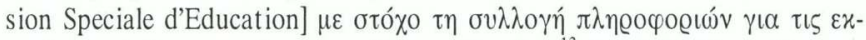

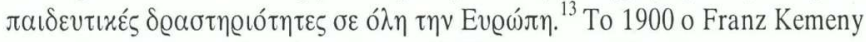

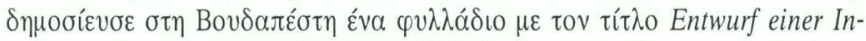

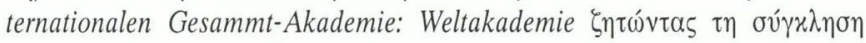

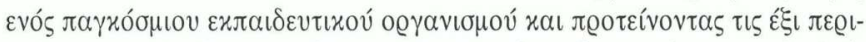

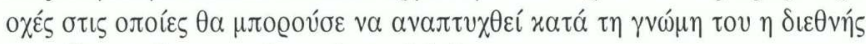

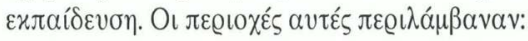

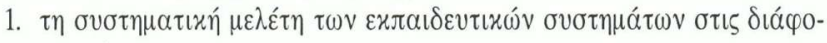

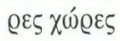

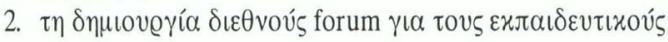

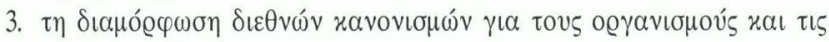

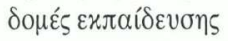

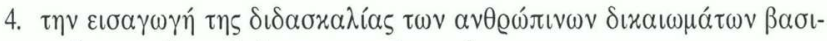

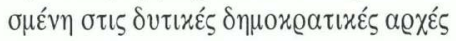

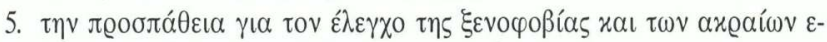

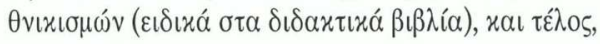

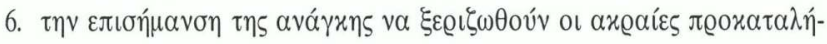
$\psi \varepsilon ı \zeta$. 


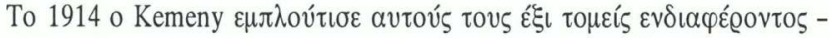

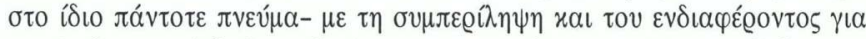

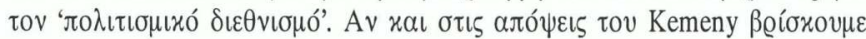

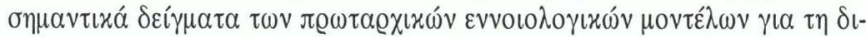

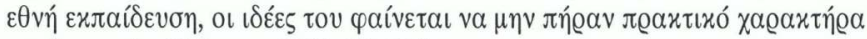

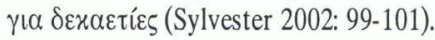

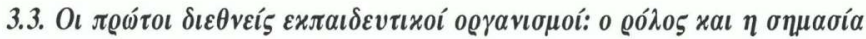 tovs}

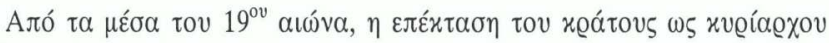

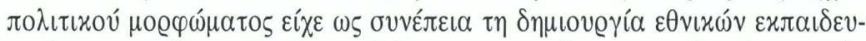

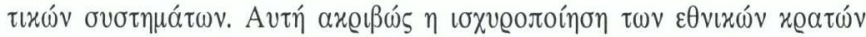

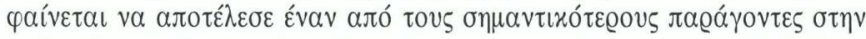

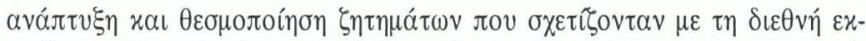

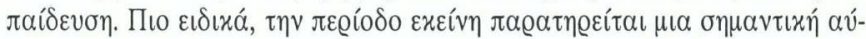

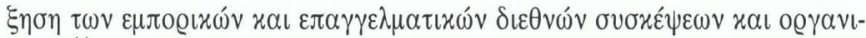

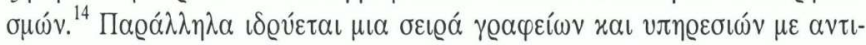

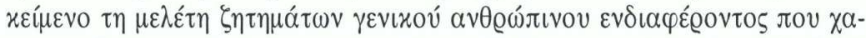

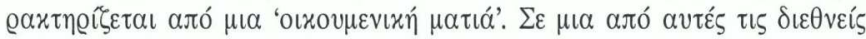

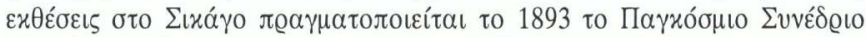

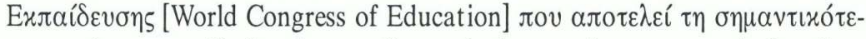

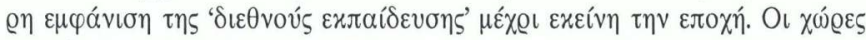

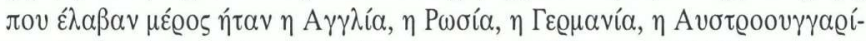

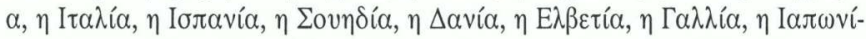

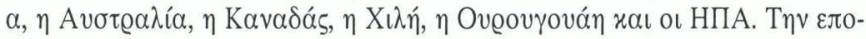

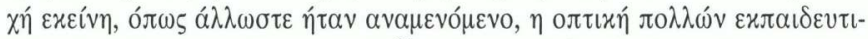

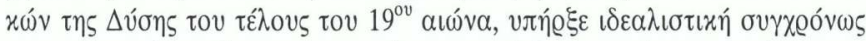

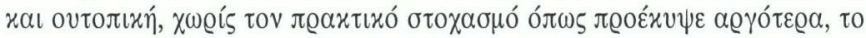

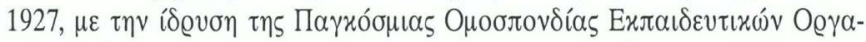

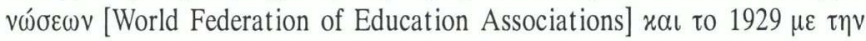

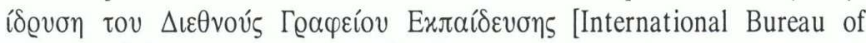

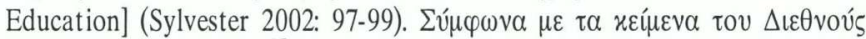

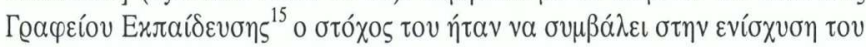

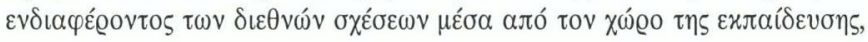




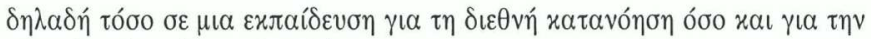

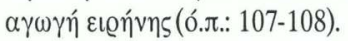

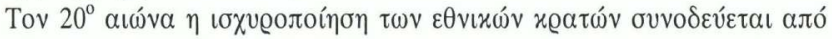

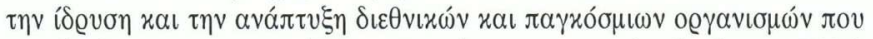

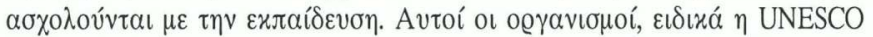

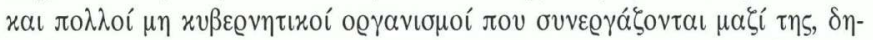

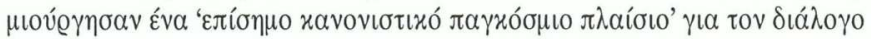

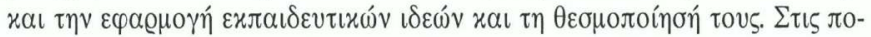

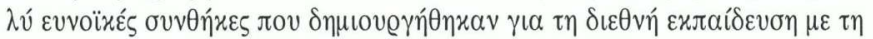

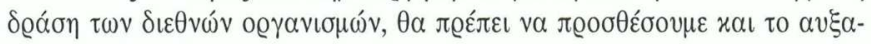
vó

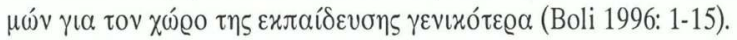

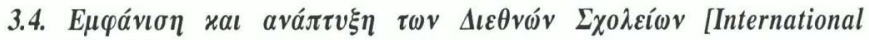 Schools]}

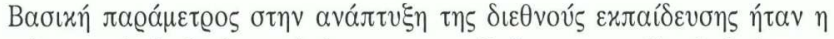

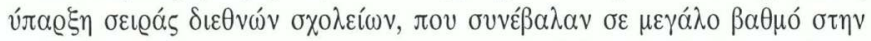

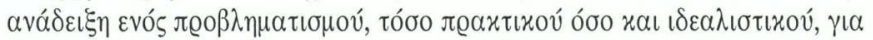

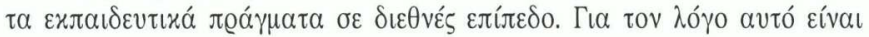

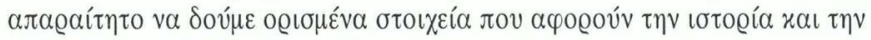

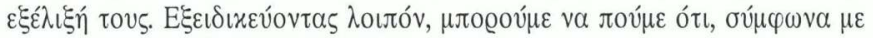

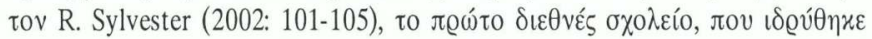

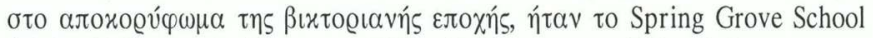

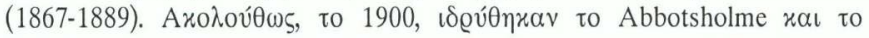

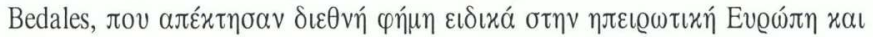

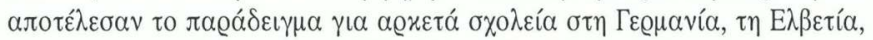

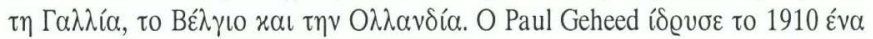

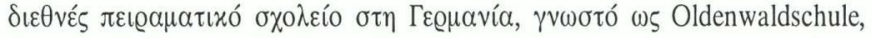

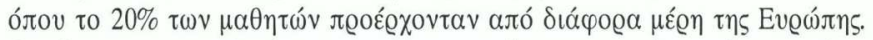

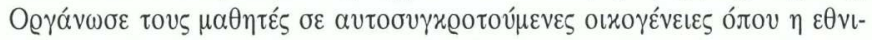

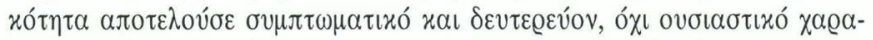

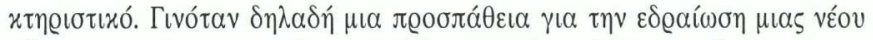

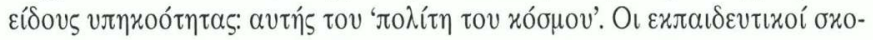

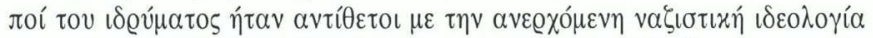

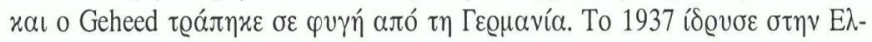




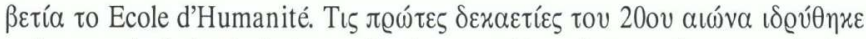

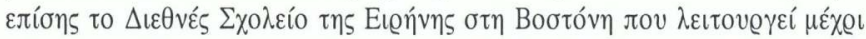
бп́

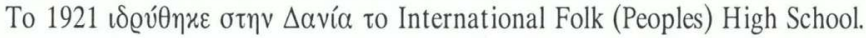

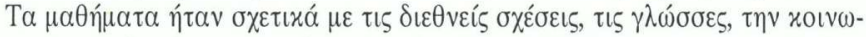

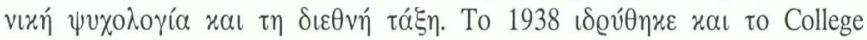

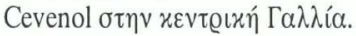

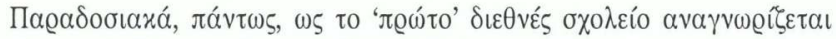

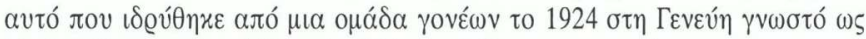

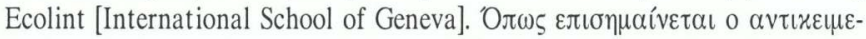

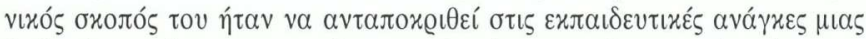

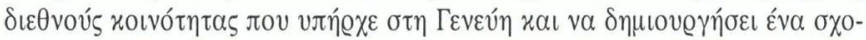

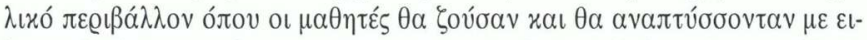

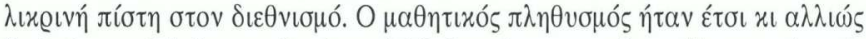

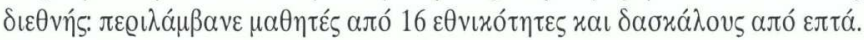

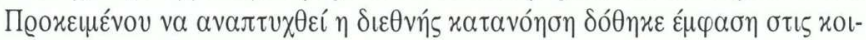

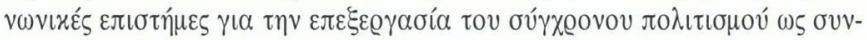

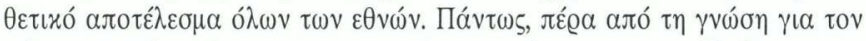

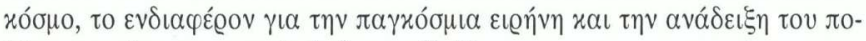

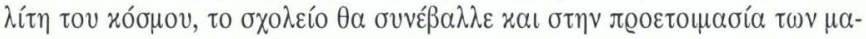

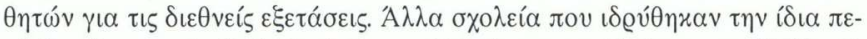

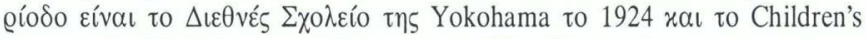

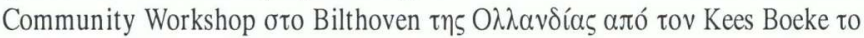
1930.

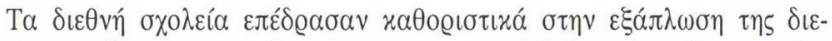

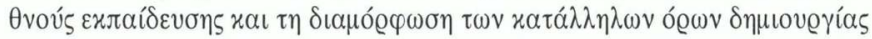

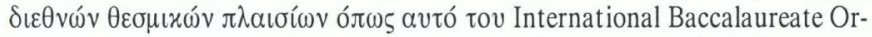

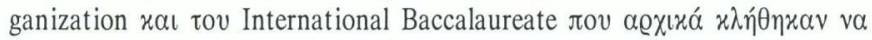

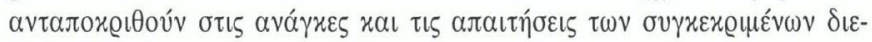

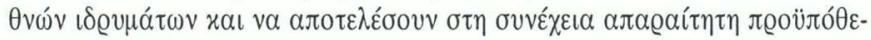

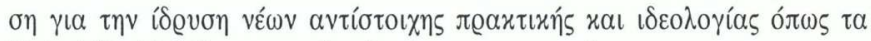

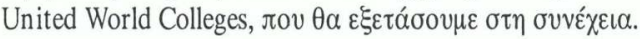




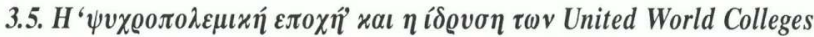

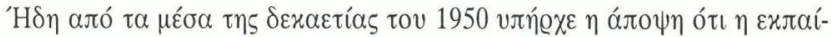

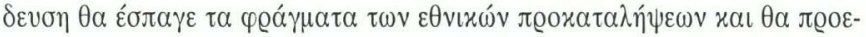

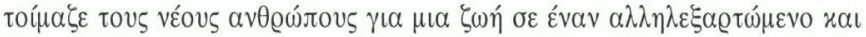

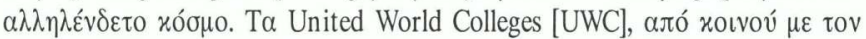

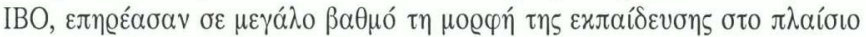

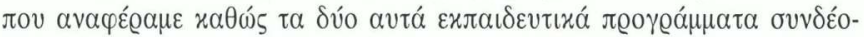

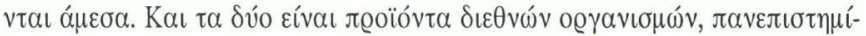

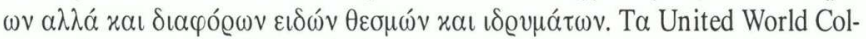

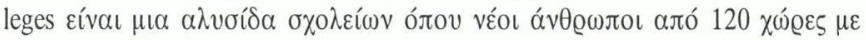

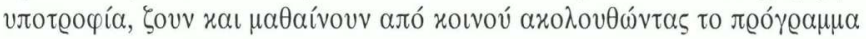
tov International Baccalaureate.

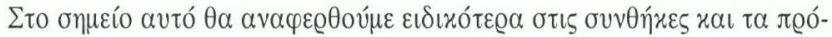

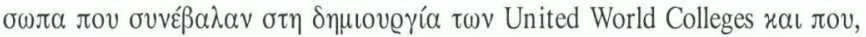

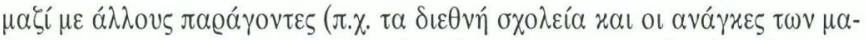

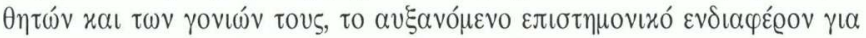

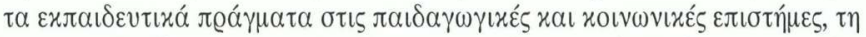

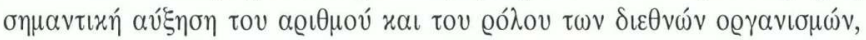

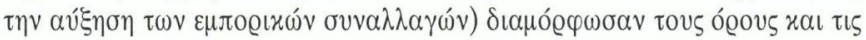

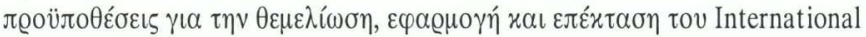

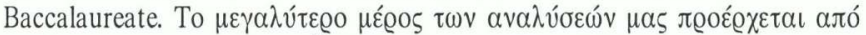

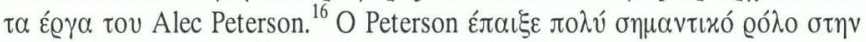

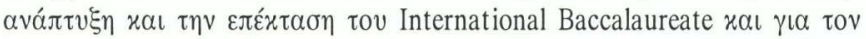

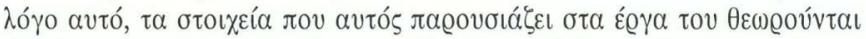

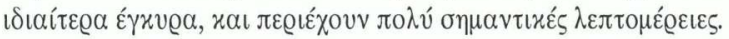

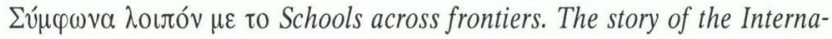
tional Baccalaureate and the United World Colleges rov Peterson (2003), ot

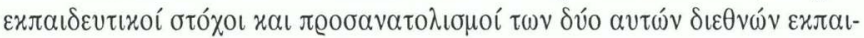

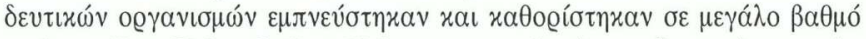

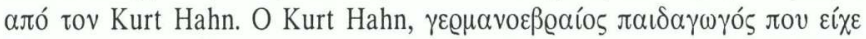

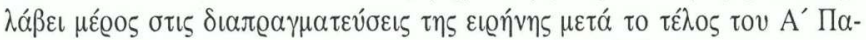

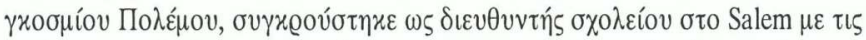

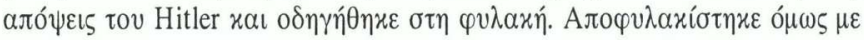

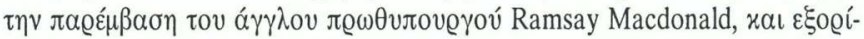

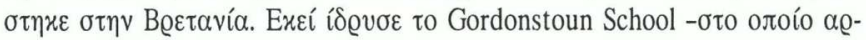




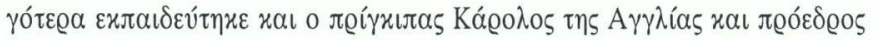

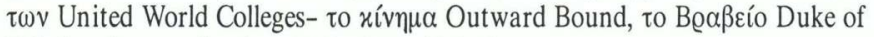

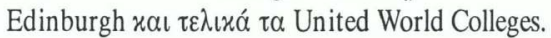

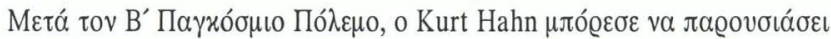

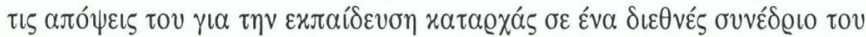

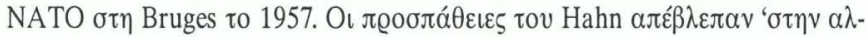

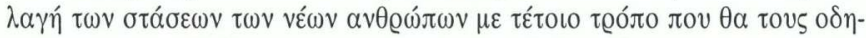

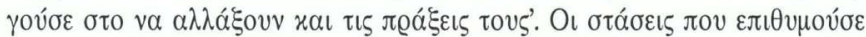

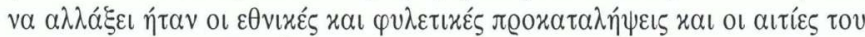

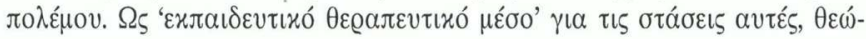

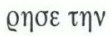

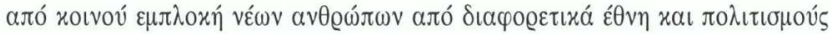

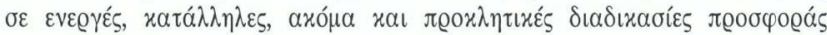

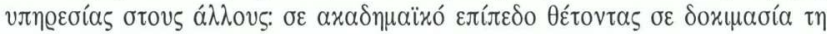

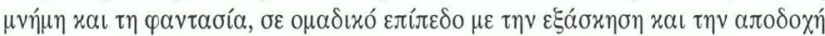

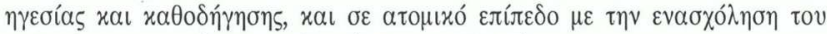

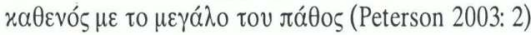

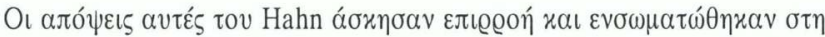

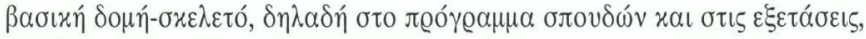

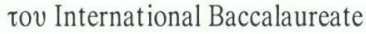

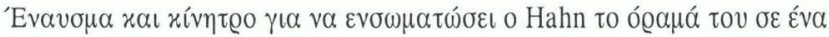

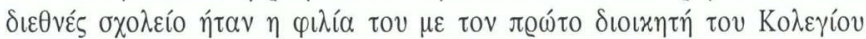

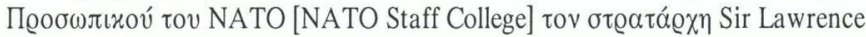

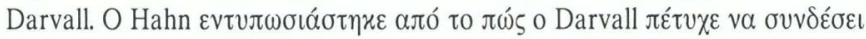

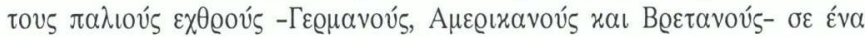

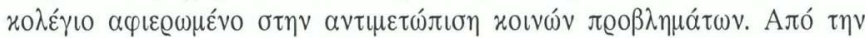

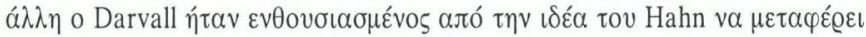

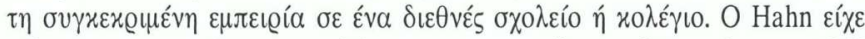

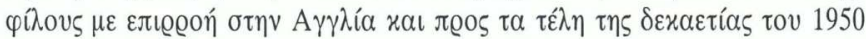

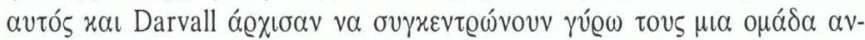

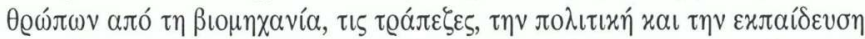

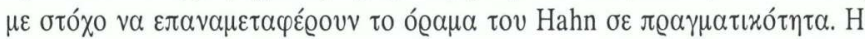

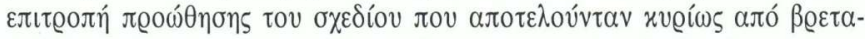

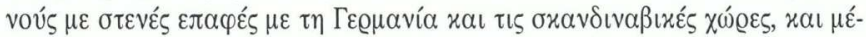

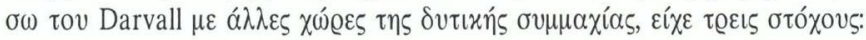




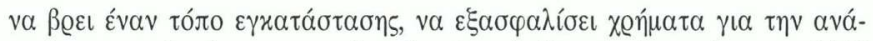

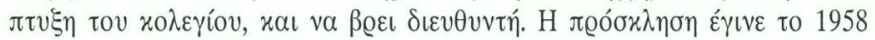

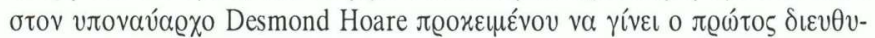

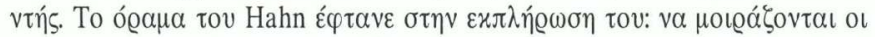

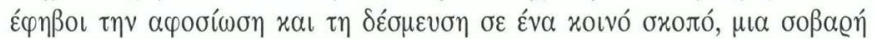

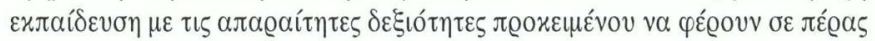

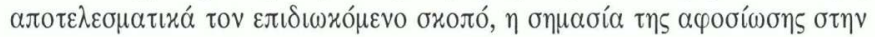

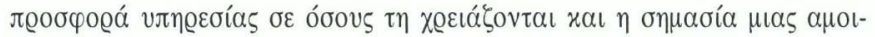

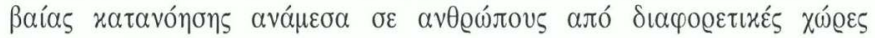
(Peterson 2003: 2-4).

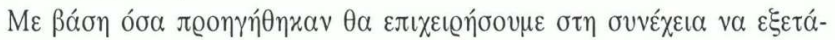

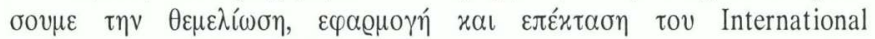

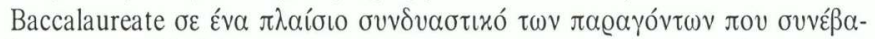

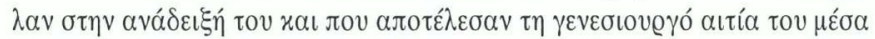

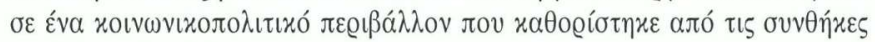

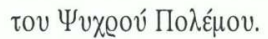

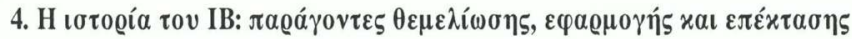

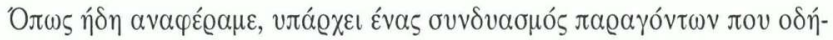

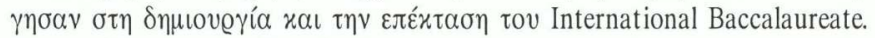

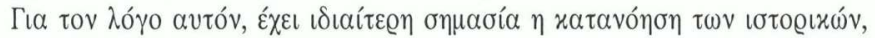

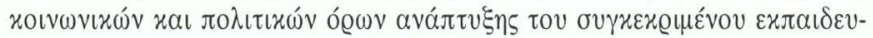

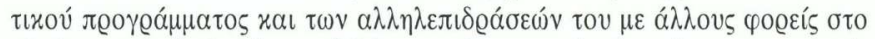

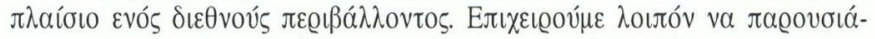

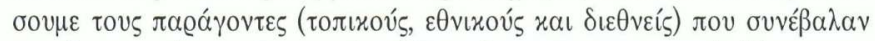

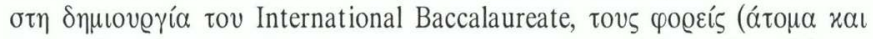

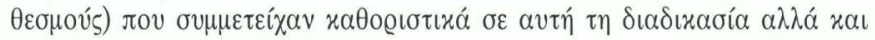

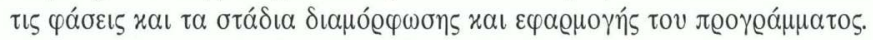

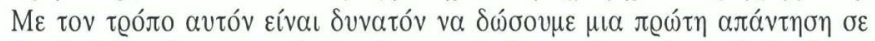

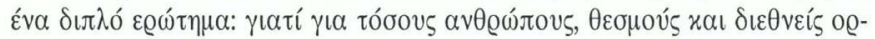

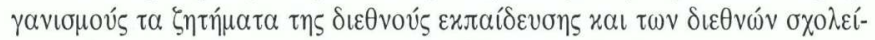

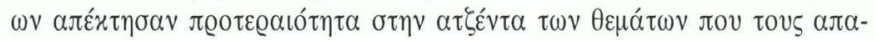

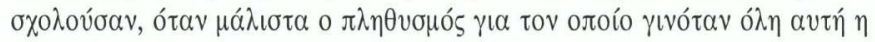

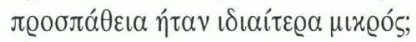




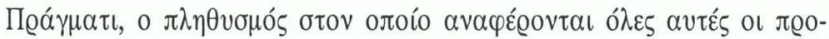

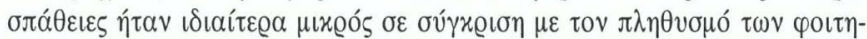

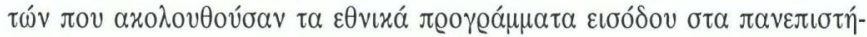

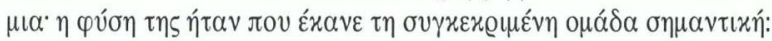

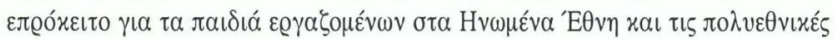

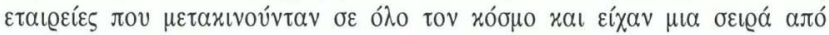

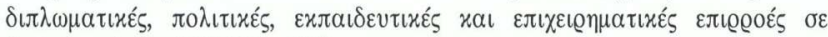

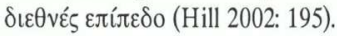

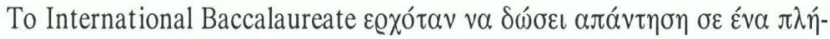

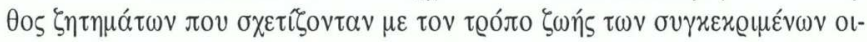

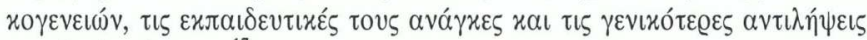

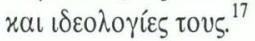

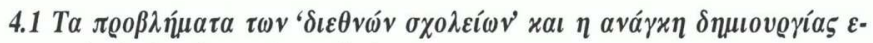

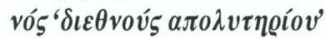

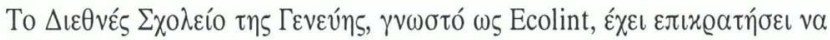

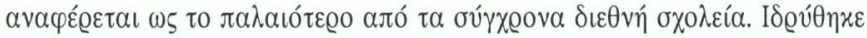

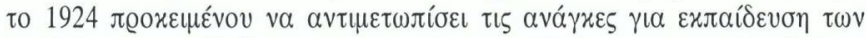

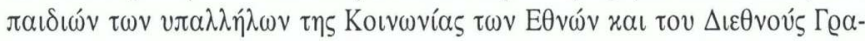

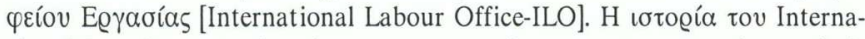

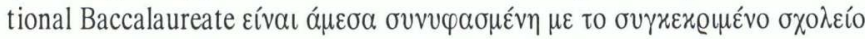

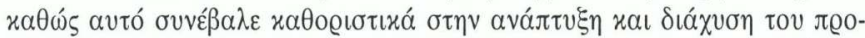

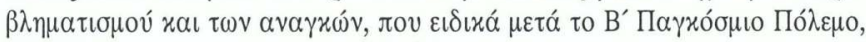

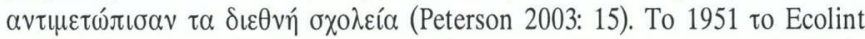

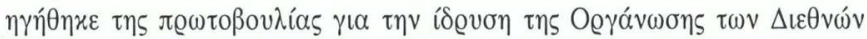

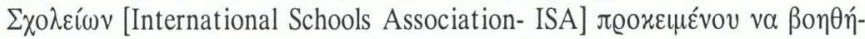

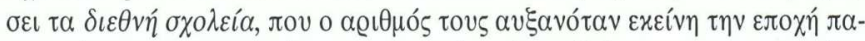

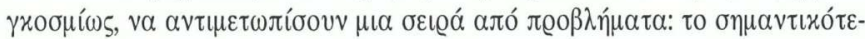

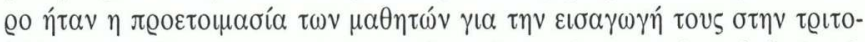

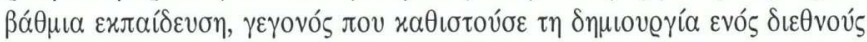

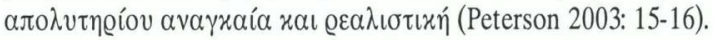

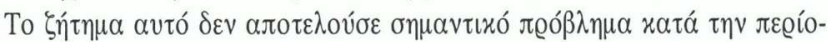

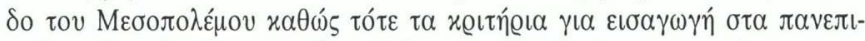

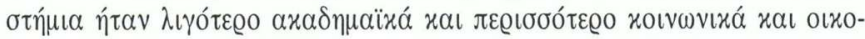

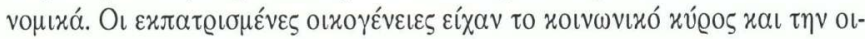




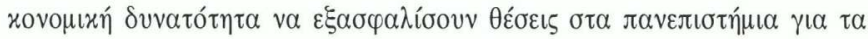

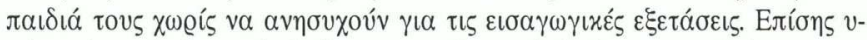

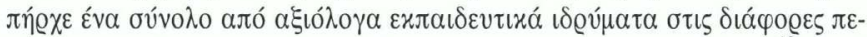

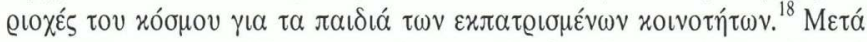

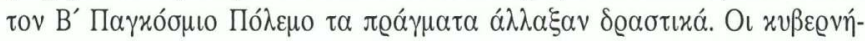

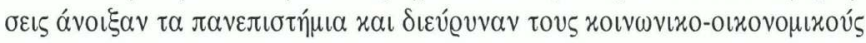

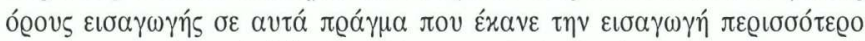

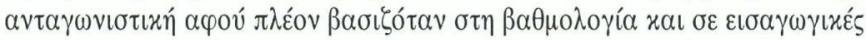

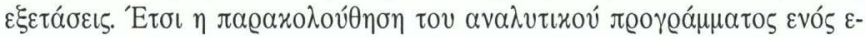

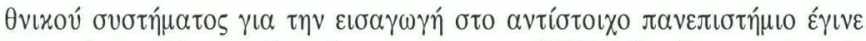

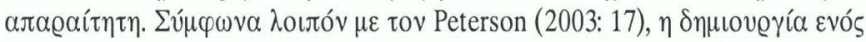

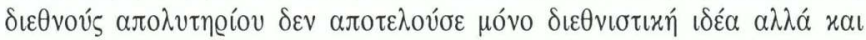

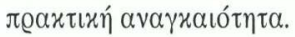

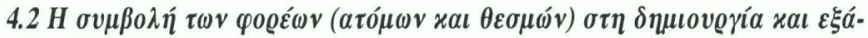 $\pi \lambda \omega \sigma \eta \tau 0 v I B$}

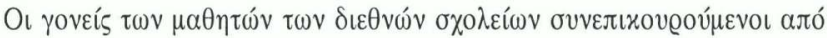

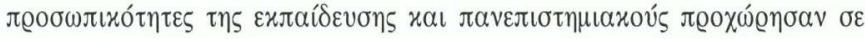

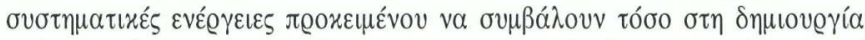

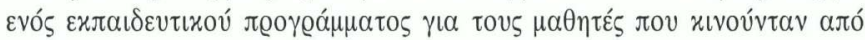

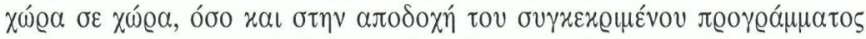

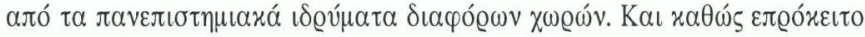

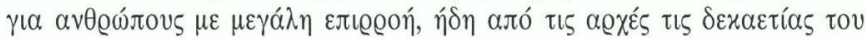

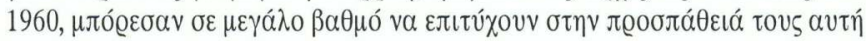
(Hill 2002: 188-189).

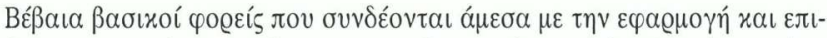

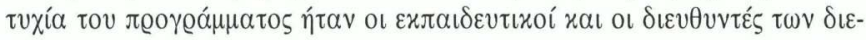

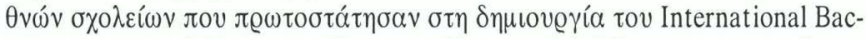

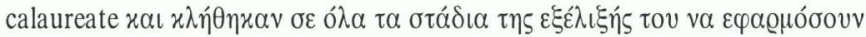

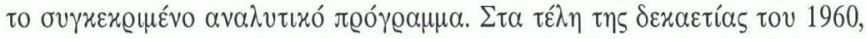

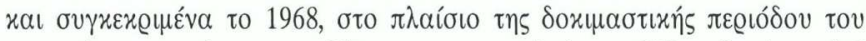

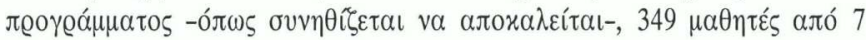

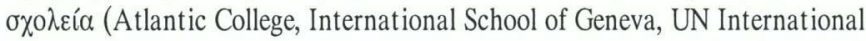
School, International College Beirut, Copenhagen International School, 
Iranzamin International School Teheran, North Manchester High School for

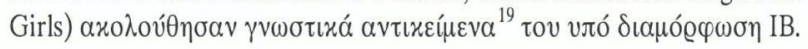

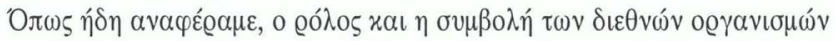

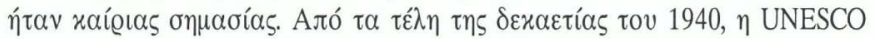

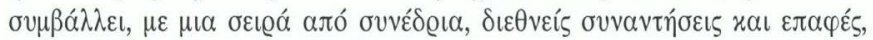

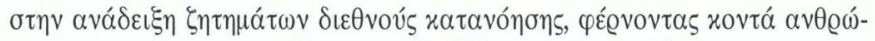

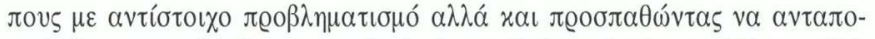

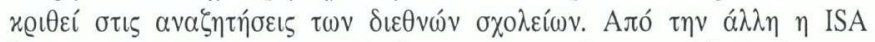

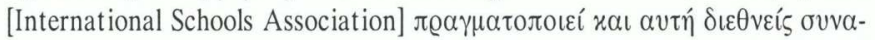

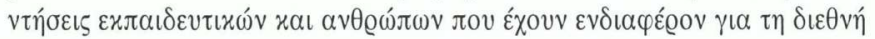

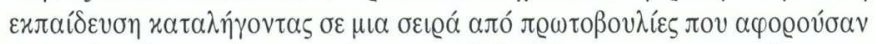

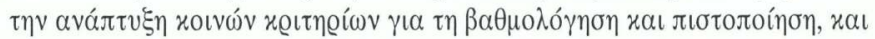

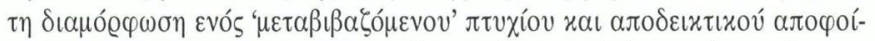

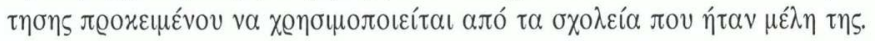

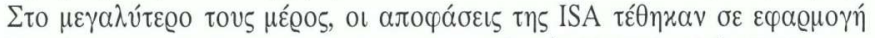

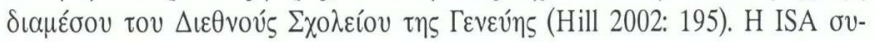

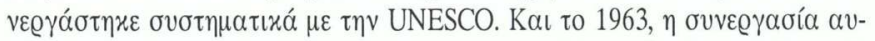

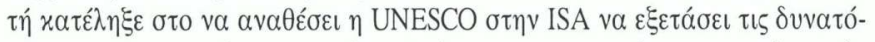

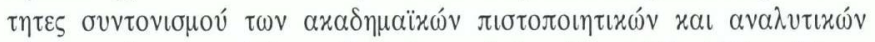

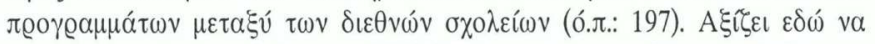

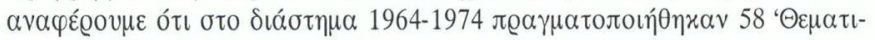

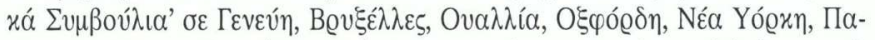

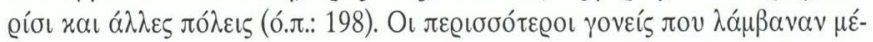

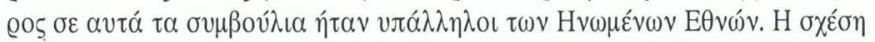

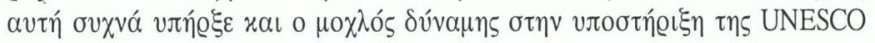

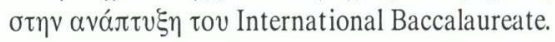

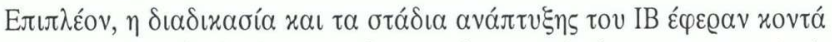

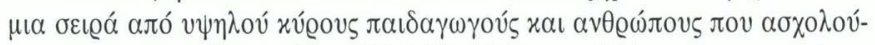

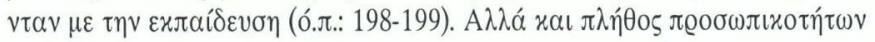

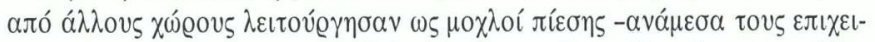

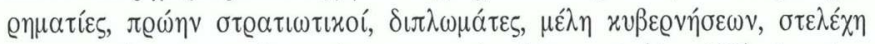

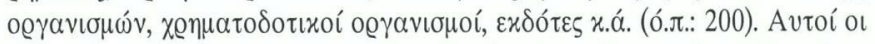

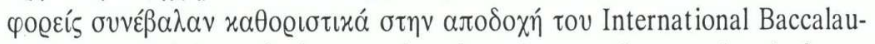

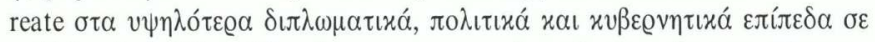

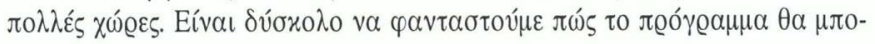




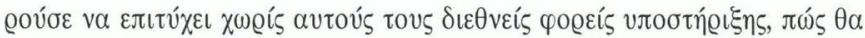

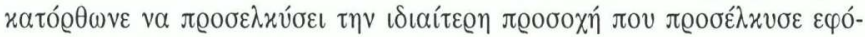

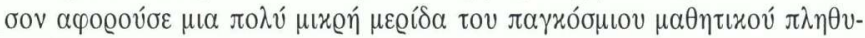
бนоú.

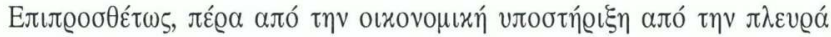

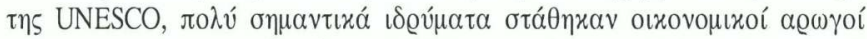

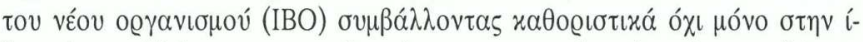

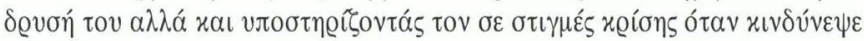

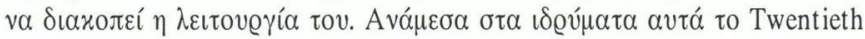

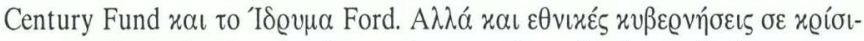

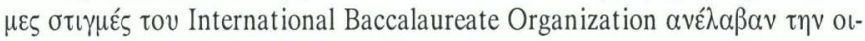

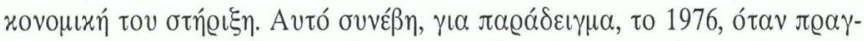

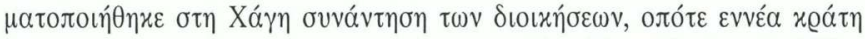

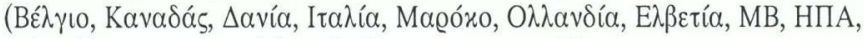

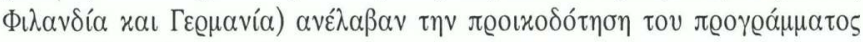

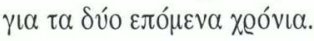

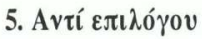

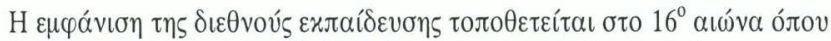
$\pi \alpha \iota \delta \alpha \gamma \omega \gamma \circ i$ ㄷ

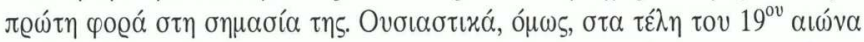

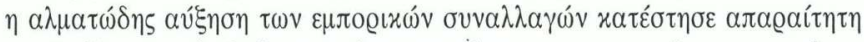

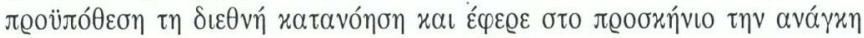

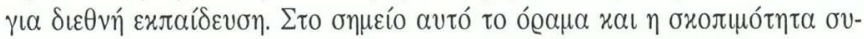

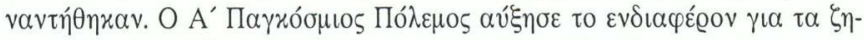

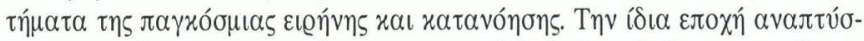

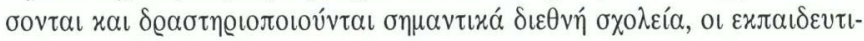

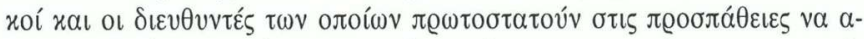

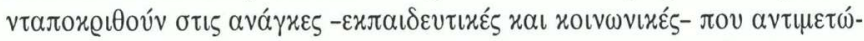

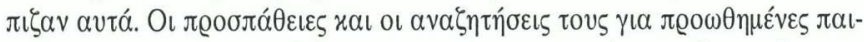

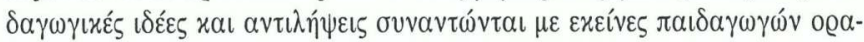

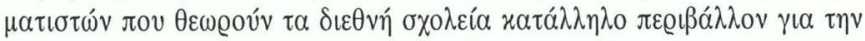

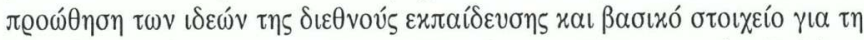

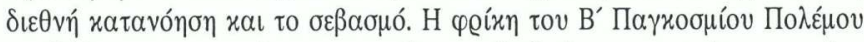

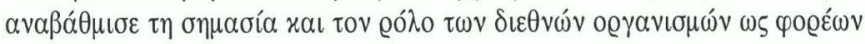




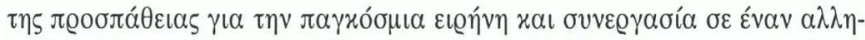
$\lambda$

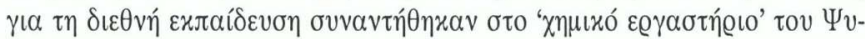

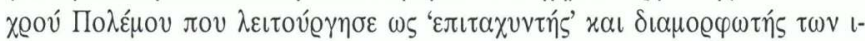

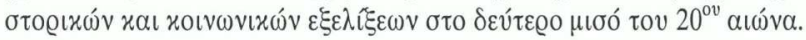

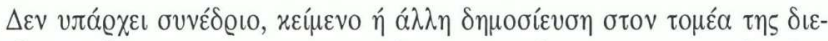

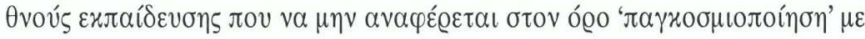

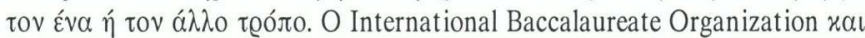

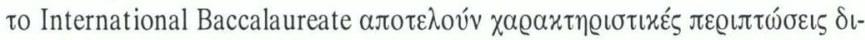

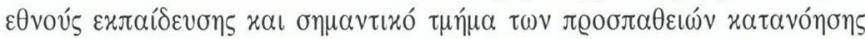

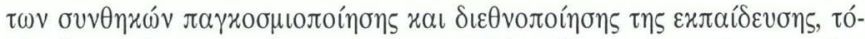

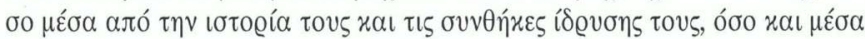

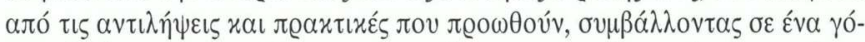

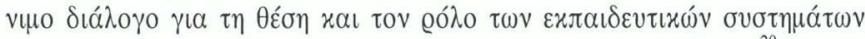

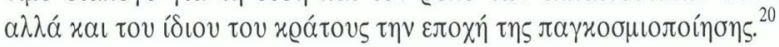

\section{$\Sigma \eta \mu \varepsilon \iota(\hat{\omega} \sigma \iota \zeta$}

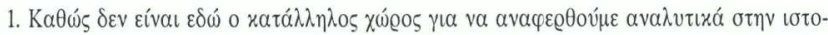

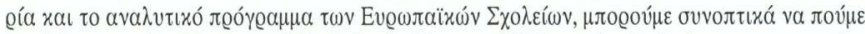

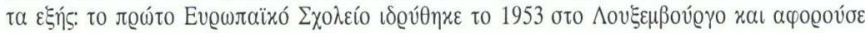

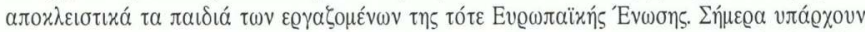

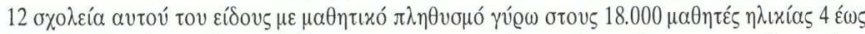

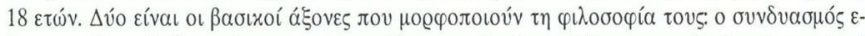

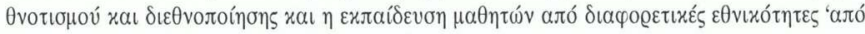

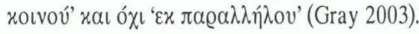

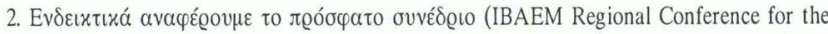

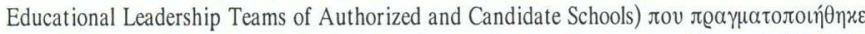

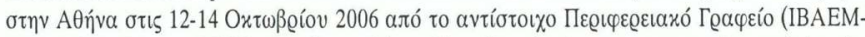
IBO Africa-Europe-Middle East) $\mu \varepsilon$ ef́na 'The IB school as a community and in the community'.

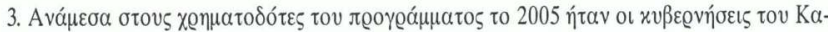

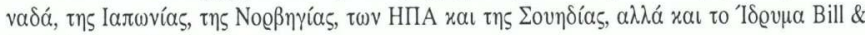
Melinda Gates (IBO 2005: 21).

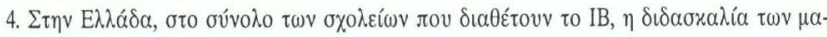

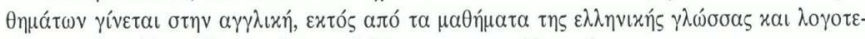

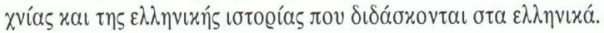




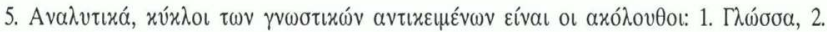

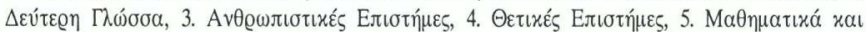

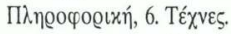

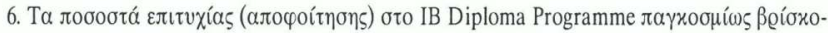

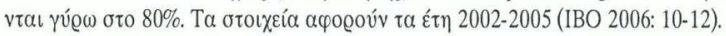

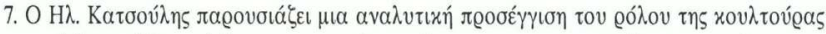

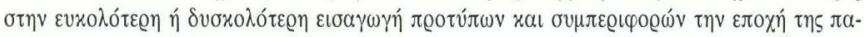

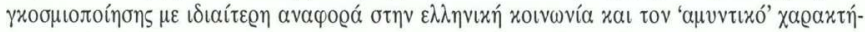

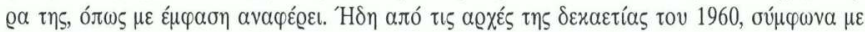

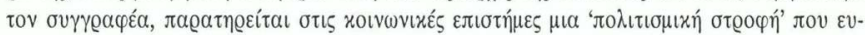

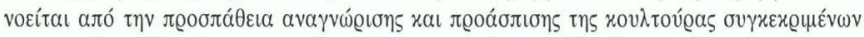

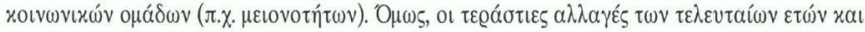

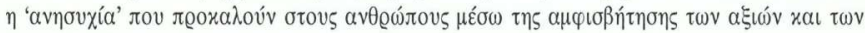

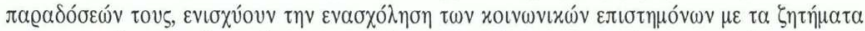

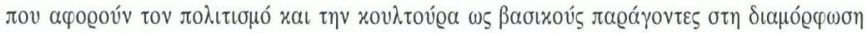

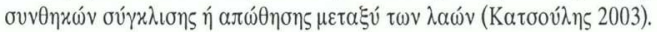

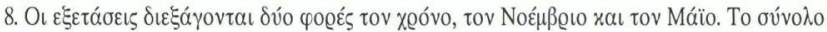

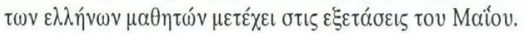

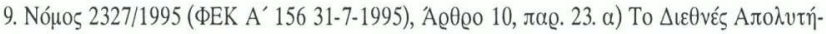

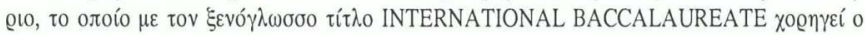

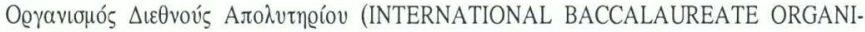

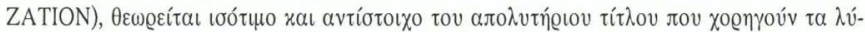

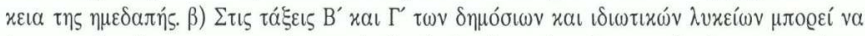

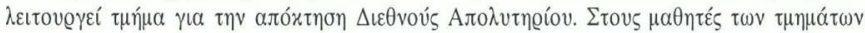

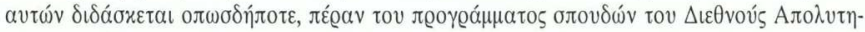

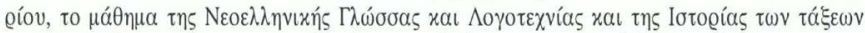

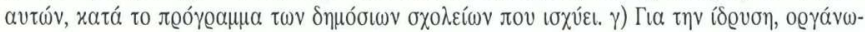

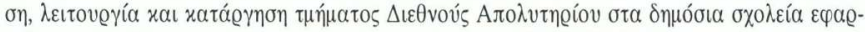

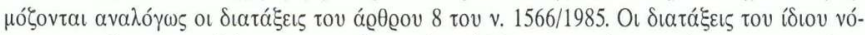

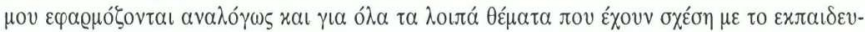

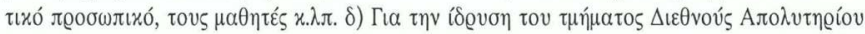

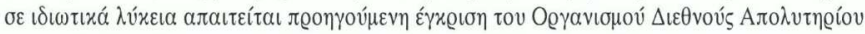

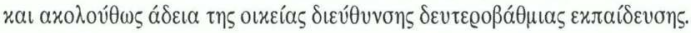

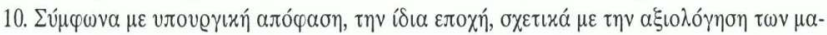

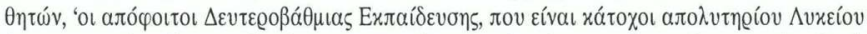

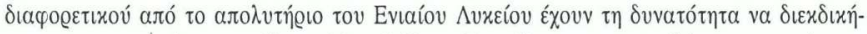

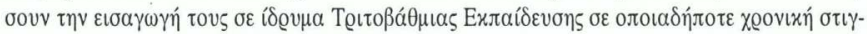

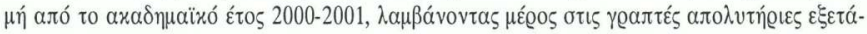

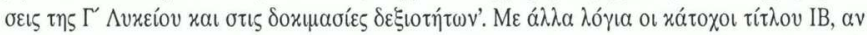

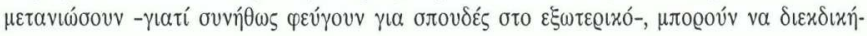




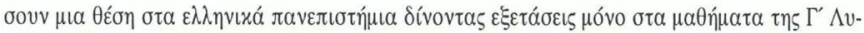

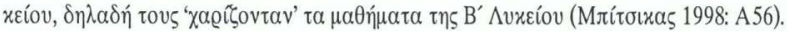

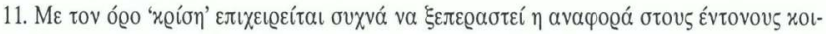

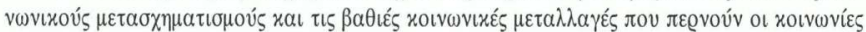

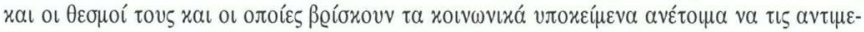

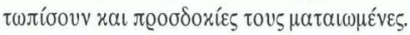

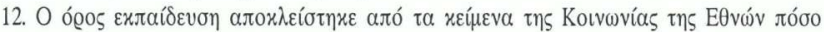

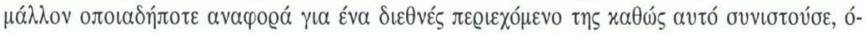

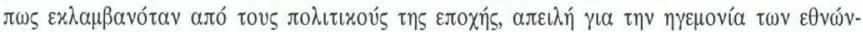

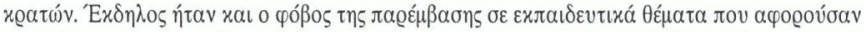

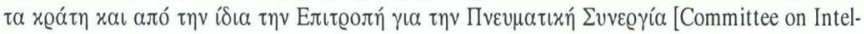

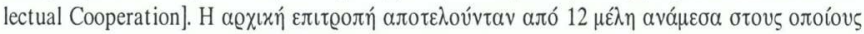

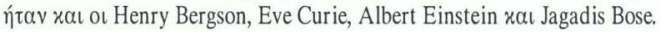

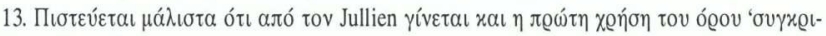

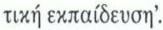

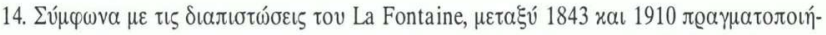

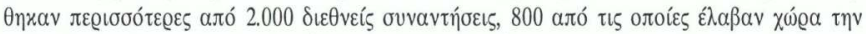

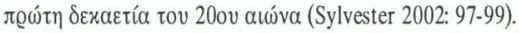

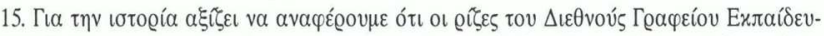

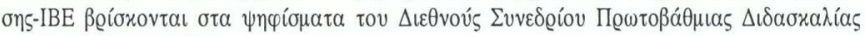

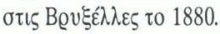

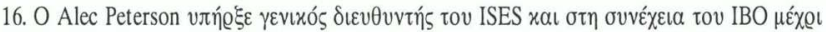

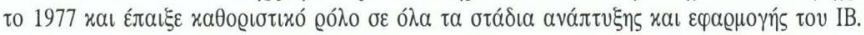

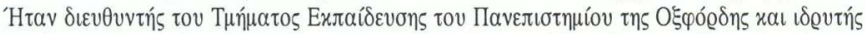

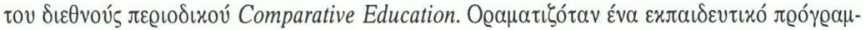

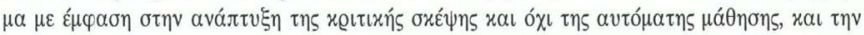

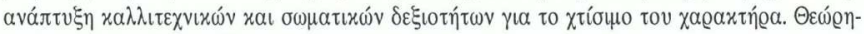

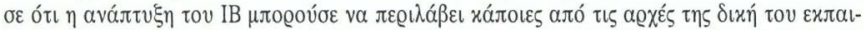

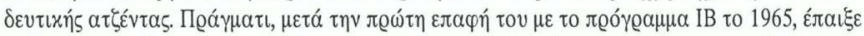

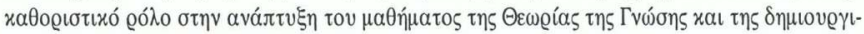

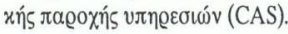

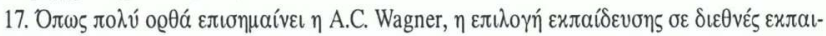

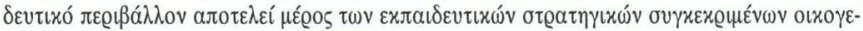

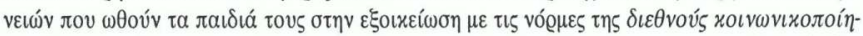

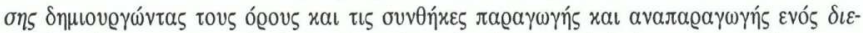

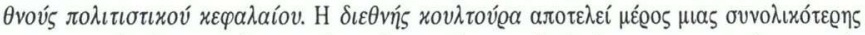

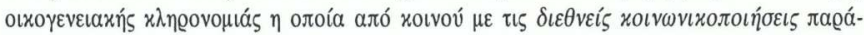

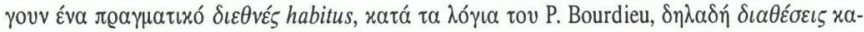

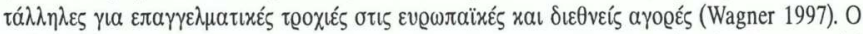

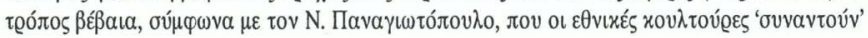




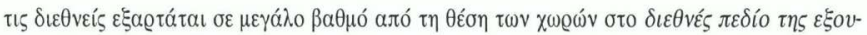

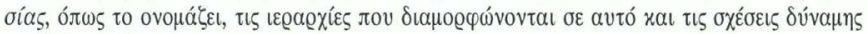

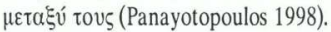

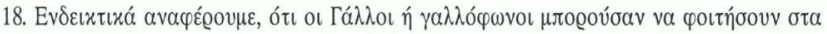

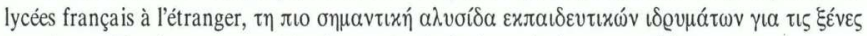

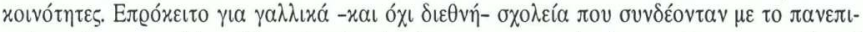

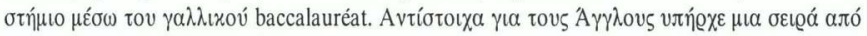

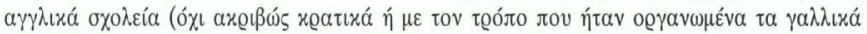

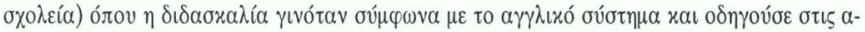

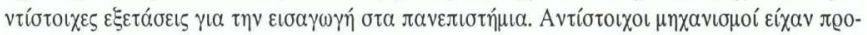

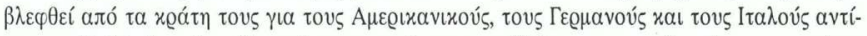

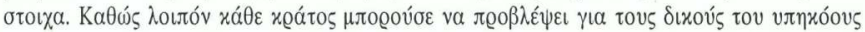

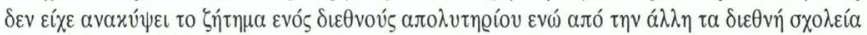

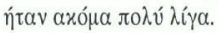

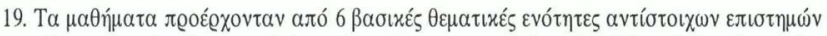

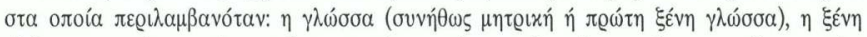

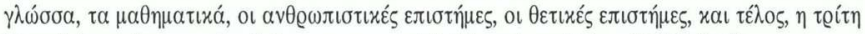

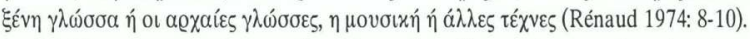

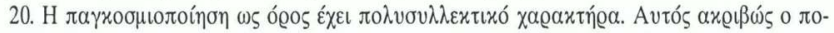

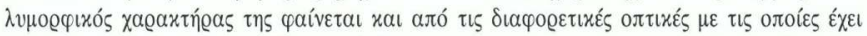

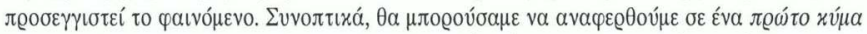

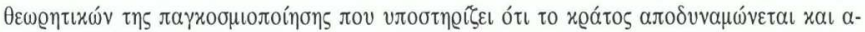

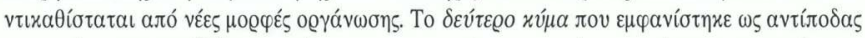

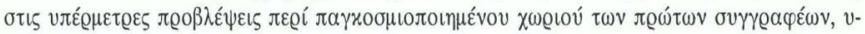

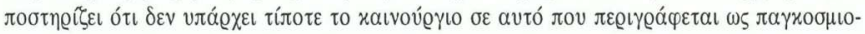

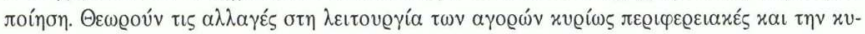

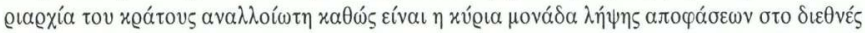

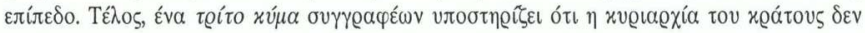

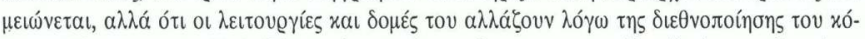

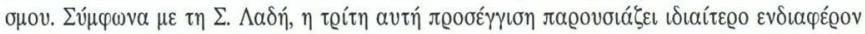

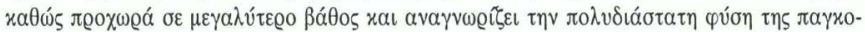

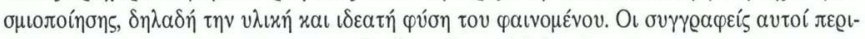

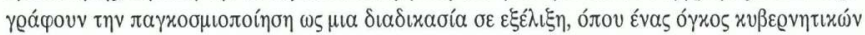

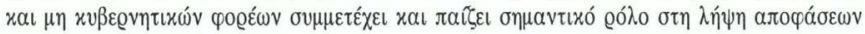

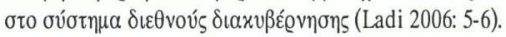




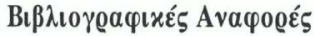

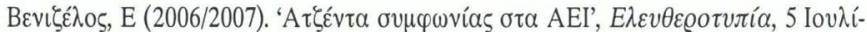

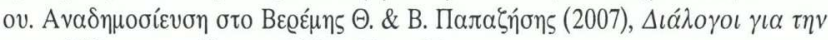

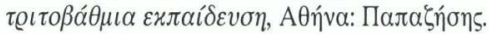

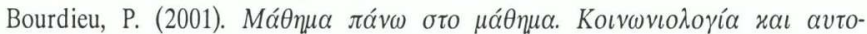

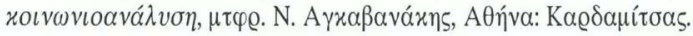

Hayden, M. (2001). 'International Education in practice', $\sigma \varepsilon$ Hayden, M., Thomp-

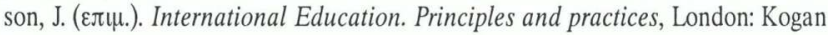
Page.

Hill, I. (2002). 'The International Baccalaureate. Policy process in education', Journal of Research in International Education, 1, 2: 183-211.

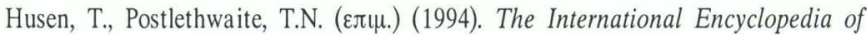
Education, Oxford: Pergamon Press.

Gray, M.R. (2003). 'Tense conjugations. Translating political values into an educational model: the European Schools, 1953-2003', Journal of Research in International Education, 2, 3: 315-330.

IBO (2005). Annual Review 2005, Geneva: IBO.

IBO (2006). 21 things you should know about the IBO, Geneva: IBO-Strategic Planning Department.

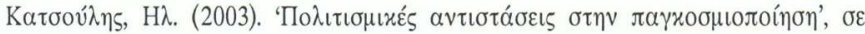

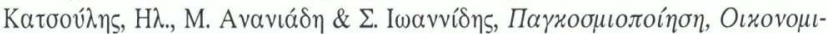

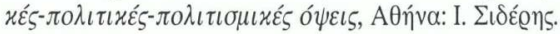

Ladi, S. (2006). 'Globalization and Europeanization: Analyzing Change', Working Paper, 4, IBEI-Institut Barcelona d' Estudis Internacional.

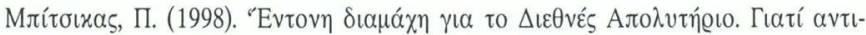

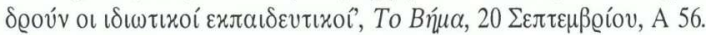

Panayotopoulos, N. (1995). 'Notes préliminaires sur l'espace de formation des cadres

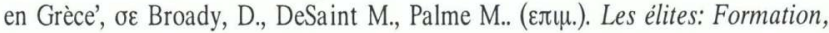
Reconversion, Internationalisation, Paris-Stockholm: Ecole des Hautes Etudes en Sciences Sociales-Lararh Ogskslan.

Panayotopoulos, N. (1998). "Les "grandes écoles" d'un petit pays. Les études à l'étranger: le cas de la Grèce', Actes de la Recherches en Sciences Sociales, 121122: 77-91.

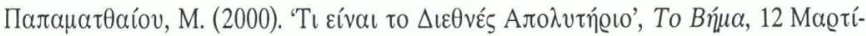
ov, A 55 . 
Peterson, A.D.C. (1972). The International Baccalaureate: an experiment in international education, London: George Harrap.

Peterson, A.D.C. (2003). Schools across frontiers. The story of the International Baccalaureate and the United World Colleges, Illinois: Open Court Publishing.

Renaud, G. (1974). Experimental period of the International Baccalaureate: objectives and results, Paris: The UNESCO Press.

Scanlon, D.G. (1960). International Education: A Documentary History, New York: Columbia University, Bureau of Publication, Teacher College.

Sylvester, R. (2002). 'Mapping International Education. A historical survey 19931944', Journal of Research in International Education, 1, 1: 90-125

Wagner, A.C. (1997). 'Les strategies transnationales en France', Skeptron Occasional Paper, 13, Stockholm. 